School of Finance

University of St.Gallen

Can Group Incentives Alleviate Moral Hazard? The Role of Pro-Social PREFERENCES

CHRISTIAN BIENER

MARTIN ELING

AMDREAS LANDMANN

SHAILEE PRADHAN

WORKING PAPERS ON FinANCE No. 2016/10

INSTITUTE OF INSURANCE ECONOMICS (I.VW - HSG)

MAY 2016 


\title{
Can Group Incentives Alleviate Moral Hazard? The Role of Pro-Social Preferences
}

\author{
BY CHRISTIAN BIENER, MARTIN ELING, ANDREAS LANDMANN, \\ AND SHAILEE PRADHAN ${ }^{*}$
}

Incentivizing unobservable effort in risky environments, such as in insurance, credit, and labor markets, is vital as moral hazard may otherwise cause significant welfare losses including the outright failure of markets. Ensuring incentive-compatibility through state-contingent contracts between principal and agent, however, is undesirable for risk-averse agents. We provide theoretical intuition on how pro-social preferences between agents in a joint liability group contract can ensure incentivecompatibility. Two independent large-scale behavioral experiments framed in an insurance context support the hypotheses derived from our theory. In particular, effort decreases when making agents' payoff less state-dependent, but this effect is mitigated with joint liability in a group scheme where agents are additionally motivated by pro-social concerns. Activating strategic motives slightly increases effort further; particularly in non-anonymous groups with high network strength. The results suggest that joint liability within groups of pro-social agents is a promising policy to improve efficiency under risk and asymmetric information. JEL Codes: D03, D81, D82, G22.

\footnotetext{
Biener: University of St. Gallen, Rosenbergstrasse 22, CH-9000 St. Gallen (e-mail: christian.biener@unisg.ch); Eling: University of St. Gallen, Rosenbergstrasse 22, CH-9000 St. Gallen (e-mail: martin.eling@unisg.ch); Landmann: Paris School of Economics and Abdul Latif Jameel Poverty Action Lab (J-PAL), 1 place du Parvis de Notre-Dame, FR-75004 Paris (alandmann@povertyactionlab.org); Pradhan: Swiss Re, Mythenquai 50/60, CH-8022 Zurich (e-mail: shailee_pradhan@swissre.com). We are grateful to the Swiss National Science Foundation (SNSF) for funding research assistant positions and field expenses. Thanks to Pascal Kieslich, Maria Isabel Santana, Nikolas Schöll, and Sven Walter for excellent research assistance. We thank Martin Brown, Dirk Engelmann, Harris Schlesinger, Joan T. Schmit, Justin Sydnor, Peter Zweifel, and the participants of the 29th Annual Congress of the European Economic Association, the American Risk and Insurance Association 2014 Annual Meeting, the 41st European Group of Risk and Insurance Economists Seminar, the 18th Conference of the Swiss Society for Financial Market Research, the ZEW/University of Mannheim Experimental Seminar, and the 2nd Research Workshop on Microinsurance for helpful comments and discussions.
} 


\section{Introduction}

Real world contracts are often simple and incomplete, falling short of specifying enforceable behavior (Kessler and Leider 2010). One important reason is the presence of information asymmetries that induce significant welfare losses, for example, if principals cannot incentivize agents' unobservable effort. This problem of moral hazard has received wide attention in the economics literature and beyond and is particularly relevant for contracts in insurance, credit, and labor markets. ${ }^{1}$ The impossibility to contract on agents' behavior implies that contracts need to condition on observable outcomes-i.e., the occurrence of specific events. The agent's payoff, thus, has to depend on the principal's state-contingent profit. $^{2}$ Ensuring incentive-compatibility through such partial risk-sharing between principal and agent, however, is undesirable for risk-averse agents (Barseghyan et al. 2013; Englmaier and Leider 2012). Pro-social preferences towards a principal can align incentives by giving the agent an intrinsic motive to exert effort (Köszegi 2014). In many—often anonymous—contractual relations, however, the principal cannot rely on such pro-social behavior. For example, few people care for the effect of their behavior on profits of large corporations. Pro-sociality is rather likely to exist between groups of agents such as colleagues and clients.

In this paper, we provide theoretical intuition and empirical evidence on how contracts can exploit pro-social preferences when those exist exclusively between agents. We investigate a group scheme, where individual agents face limited risk as they are jointly liable for the contractual outcome, and analyze efficiency as well as effectiveness of the scheme for mitigating moral hazard. The basic logic is that under joint liability, effort provision is a public good-though in a risky environment- to which pro-social individuals contribute more than their private benefit would suggest. As a consequence, the payoff of agents in groups needs to depend less on individual performance to induce effort than under idiosyncratic contracts. This logic is consistent with a relatively new stream of theoretical research which explains flat wage structures within firms with pro-social concerns of agents (Itoh 2004; Bartling and Siemens 2010; Englmaier and Wambach 2010; Nielson and Stowe 2010; Bartling 2011, 2012). We analyze moral hazard based on an insurance model (adapted from Ehrlich and Becker 1972) to which we add a joint liability group scheme in addition to pro-social preferences. This theoretical part hence provides an intuition tailored to our empirical setup, but the framing can be easily adapted to other settings such as employment contracts.

Our theoretical contribution is mainly complementary to the existing literature. However, to the best of our knowledge we are the first to show empirically that pro-social preferences between agents can be exploited to increase efficiency in risky environments which are prone to moral hazard. This is

\footnotetext{
${ }^{1}$ See for instance Arrow (1963), Pauly (1968), Zeckhauser (1970), Spence and Zeckhauser (1971), Pauly (1974), and Holmström (1979). See Rowell and Connelly (2012) for a recent review of the history of the term "moral hazard."

${ }^{2}$ Complete observation of actions and, thus, conditioning contracts on monitored actions is either impossible or prohibitively expensive (Holmström 1979; Shavell 1979; Arnott and Stiglitz 1991). A stream of experimental research has investigated how punishment in repeated interactions can mitigate moral hazard when behavior of the agent can be inferred by the principal after each period (see, e.g., Brown, Falk, and Fehr 2004; Brown and Zehnder 2007; Fehr, Brown, and Zehnder 2009; Babcock et al. 2015).
} 
by no means a trivial finding. Whereas there is some evidence suggesting that pro-social contributions are lower in risky settings as opposed to deterministic settings (Berger and Hershey 1994; Gong, Baron, and Kunreuther 2009), the group setting might induce a common identity, which has been shown to increase public good contributions (Eckel and Grossmann 2005; Kramer and Brewer 1986). So it is hitherto unclear whether joint liability groups can stimulate significant cooperation under risk and if so, whether this translates into higher efficiency of such schemes.

Our results are based on two distinct large-scale behavioral experiments conducted in the field with rural villagers from the Philippines and in the computer laboratory with university students from Germany. The experiments are framed in an insurance setting and participants can decide whether or not to provide self-protection (i.e., effort to decrease the likelihood of a loss) under different insurance contracts. In line with moral hazard, we find that effort decreases when making payoffs of agents less state-dependent (i.e., increasing insurance coverage). A group scheme with joint liability, however, performs significantly better in terms of incentivizing effort given similar levels of risk-exposure. This is consistent with our theoretical results and implies potential efficiency gains from group schemes in the presence of pro-social preferences. We further find that pro-sociality might be driven by reciprocal concerns. In particular, for those with positive beliefs about their group peer's effort we find a higher likelihood to provide effort. Activating strategic motives through revealing effort choices of agents increases efficiency of the group scheme further, in particular when strategic motives are salient through non-anonymity of agents. The main results hold separately in both the German and the Philippine samples, suggesting that the effect is to some extent robust across cultures and different levels of experience with financial services.

Group incentives as a remedy for moral hazard have received broader attention in the recent literature. The discussion of team incentives in employment contracts is probably closest to our paper. Classic fixed-wage employment contracts often accompany reduced effort provision and, thus, moral hazard (Shearer 2004), whereas explicit incentives, such as those inherent in piece rate wages (Dewatripont, Jewitt, and Tirole 1999), simple lump-sum bonus contracts (Herweg, Müller, and Weinschenk 2010; Biais et al. 2010), and competitive schemes (Goette et al. 2012; Guillen, Merrett, and Slonim 2015) induce effort but might be unattractive to risk-averse individuals. In contrast, inequity concerns (Fehr and Schmidt 1999) of agents towards a principal as well as towards other agents have been shown to provide a potential remedy for moral hazard in theory (see Köszegi 2014 for a summary of the literature).

Joint liability group schemes are also considered in the microfinance literature where moral hazard is seen as a likely explanation of credit constraints and credit market failures for low-income populations (Adams, Einav, and Levin 2009; Visaria 2009; Giné, Goldberg, and Yang 2012). Arnott and Stiglitz (1991) emphasize the value of informal contract enforcement through peer monitoring for solving moral hazard problems. The more recent literature shows how group-lending contracts can alleviate moral hazard, both theoretically (Ghatak and Guinnane 1999) and empirically (Karlan 2005; 
Karlan 2007; Al-Azzam, Hill, and Sarangi 2012; Bauer, Chytilová, and Morduch 2012; Giné and Karlan 2014). However, most theoretical models do not deviate from assuming self-interested agents. Contract enforcement through peer monitoring, thus, restricts efficiency improvements induced by groups to cases where group members have better information and punishment possibilities. Such schemes have limited value in situations where effort provision and, hence, moral hazard is truly unobservable, as in our setup.

While moral hazard is of crucial importance in insurance markets and has generated a large literature addressing both theoretical issues (Ehrlich and Becker 1972; Pauly 1974) and empirical tests (Chiappori and Salanié 2000; Yilma, Kempen, and Hoop 2012; Dionne, Michaud, and Dahchour 2013; Autor, Duggan, Gruber 2014), there is surprisingly little discussion about leveraging group incentives to mitigate moral hazard. The most common remedy to moral hazard is partial risk-sharing (for example, through co-payments and deductibles), but this most negatively affects those with high insurance demand - that is, risk-averse individuals. For those, group schemes may be particularly valuable. One might attribute the lack of literature in the insurance context to the scarcity of realworld applications, as opposed to the labor (Che and Yoo 2001) or microcredit market (Hermes and Lensink 2007). However, joint liability in insurance is not merely a theoretical construct, but is in fact widespread. Especially in developing countries, community-based risk management is the norm rather than the exception (Bhattamishra and Barrett 2010). Arrangements, such as small local self-help groups, are extreme examples of joint liability without any link to formal insurance. Other arrangements combine formal insurance with joint liability, such as the mutual insurance funds model Fondos in Mexico (World Bank 2013). In developed countries, "peer-to-peer" insurance schemes, such as Friendsurance (Germany), Hey Guevara (United Kingdom), and PeerCover (New Zealand), are becoming more popular. While these examples show that joint liability group schemes in insurance are relevant in practice, the incentive mechanisms at work are still not well understood.

The remainder of this paper proceeds as follows. In Section II, we introduce our theoretical framework and discuss the incentive effects of joint liability. Section III contains a description of the experimental design and sampling procedures. In Section IV, we present the research questions in the context of our setup and derive hypotheses. Section V discusses our results and in Section VI, we conclude.

\section{Incentives for Effort Provision}

This section describes how moral hazard emerges under individual and group contracts. Theory predicts that effort decreases when the private payoff of agents becomes less state-dependent under both individual and group contracts. Typically, however, it is assumed that agents are self-interested. We show how agents' decisions in group schemes depend on whether they exhibit preferences consistent with pro-social motives towards their fellow agents and how such preferences can align incentives and alleviate moral hazard. To this end, we rely on an insurance model originating from Ehrlich 
and Becker (1972) and their successors. ${ }^{3}$ The setup, however, can be readily extended to other settings such as labor markets, where instead of varying degrees of insurance coverage the incentivized share of the total wage varies (i.e., piece rate versus fixed wage). Furthermore, random shocks would not determine claim incidences but the level of profit for the enterprise in this case.

\section{A. Optimal Effort in the Absence of Insurance}

Consider an individual with von Neumann-Morgenstern utility function $U(),. U^{\prime}()>$.0 and initial wealth $W$, which is subject to a random loss $L<W$ with probability $p$. The state of nature $z \in$ $\{0,1\}$ indicates whether a loss occurred $(z=1)$ or not $(z=0)$. The individual can reduce $p$ by investing effort $e$ in self-protection. The probability $p$ thus becomes a function of $e$ for which $p^{\prime}(e)<0$. The individual's final wealth is $Y_{z}=W-e-L \cdot 1_{z=1}$. The optimal investment in self-protection effort $e^{*}$ would maximize the individual's expected utility (EU):

$$
\text { (1) } E U=p(e) U\left(Y_{1}\right)+[1-p(e)] U\left(Y_{0}\right) \text {, }
$$

where $Y_{0}=W-e$ and $Y_{1}=W-e-L$. The first-order condition $\partial E U / \partial e$ for optimizing Equation (1) with respect to $e$ is as follows:

$$
\text { (2) }-p^{\prime}(e)\left[U\left(Y_{0}\right)-U\left(Y_{1}\right)\right]=p(e) U^{\prime}\left(Y_{1}\right)+(1-p(e)) U^{\prime}\left(Y_{0}\right) \text {. }
$$

The first term in Equation (2) is the marginal utility gain from the reduction in $p$. For the firstorder condition to hold, the marginal utility gain from self-protection must equal the marginal utility loss from reducing wealth $Y$ in both states, which is reflected in the term on the right-hand side of Equation (2). Briys and Schlesinger (1990) show that the optimal level of self-protection $e^{*}$ can either increase or decrease in risk aversion. This relationship is intuitive because the cost of self-protection makes the worst possible outcome even worse, although the probability of the worst possible outcome is reduced. Jullien, Salanié, and Salanié (1999) further show that if the initial loss probability is low, more risk-averse agents prefer to self-protect, whereas if the loss probability is high, they prefer to reduce losses in the unfavorable state of the world, thus reducing self-protection because of its costs. The optimal level of self-protection $e^{*}$ thus depends on the initial loss probability $p$ and the level of risk aversion. ${ }^{4}$

\section{B. Optimal Effort under Individual Insurance}

Following Pauly (1974), we can represent different degrees of insurance by $x$ units of insurance coverage at premium cost $c$ per unit. An equivalent situation can be created via insurance with $D=$

\footnotetext{
${ }^{3}$ Additions to and extensions of the interplay between self-protection effort and insurance are found in Dionne and Eeckhoudt (1985), Hiebert (1989), Briys and Schlesinger (1990), Briys, Schlesinger, and Schulenburg (1991), Sweeney and Beard (1992), Konrad and Skaperdas (1993), Jullien, Salanié, and Salanié (1999), Courbage (2001), Lakdawalla and Zanjani (2005), Muermann and Kunreuther (2008), and Lohse, Robledo, and Schmidt (2012). Our formal representation draws heavily on Briys and Schlesinger (1990).

${ }^{4}$ Dionne and Eeckhoud (1985) provide differentiated results regarding ranges of initial probabilities for a selection of utility functions. For quadratic utility functions, they show that self-protection increases (decreases) with risk aversion if $\mathrm{p}<(>) 0.5$. The results for logarithmic and exponential utility functions are ambiguous.
} 
$L-x$ units of deductible; we use this deductible notation to analyze insurance with different deductible arrangements. We follow Rothschild and Stiglitz (1976), Holmström (1979), and Shavell (1979), among others, by assuming that the insurer cannot observe the individual's self-protection decision and thus cannot condition $c$ on self-protection $e .{ }^{5}$ Final wealth thus changes to $Y_{z}=W-e-c \cdot(L-$ $D)-D \cdot 1_{z=1}$, and hence the difference $U\left(Y_{0}\right)-U\left(Y_{1}\right)$ is increasing in the deductible $D$. Again, we calculate the optimal provision of self-protection effort $e^{*}$ by maximizing the individual's EU, such that Equation (2) is fulfilled. It is straightforward to see that in the case of full insurance ( $x=L \Leftrightarrow$ $D=0)$, there is no incentive for self-protection because $U\left(Y_{0}\right)=U\left(Y_{1}\right)$ and the marginal benefit of self-protection becomes zero. Without coverage $(x=0 \Leftrightarrow D=L)$, the incentive is equivalent to the no-insurance case. Generally, the marginal benefit of self-protection effort on the left-hand side of Equation (2) is decreasing in insurance coverage. The behavior of the right-hand side is less clear and will depend on the exact specification of the utility function and its parameters. As Pauly (1974) argues, however, it is straightforward to construct examples in which optimal self-protection is monotone and decreasing in insurance coverage. The implication of this result for our experiments is that levels of self-protection under individual insurance should be below the no-insurance case and decrease with insurance coverage (i.e., increase with the deductible).

\section{Optimal Effort under Group Insurance}

In the moral hazard model of Arnott and Stiglitz (1991), individual insurance (i.e., market insurance) and risk sharing in social groups (i.e., nonmarket insurance) are treated as two competing approaches. Nonmarket insurance solves moral hazard only when self-protection effort is observable. Here, we unite market and nonmarket insurance under a group insurance scheme. ${ }^{6}$ This concept includes a contractually agreed-upon mutual sharing of losses (joint liability) below a deductible, a feature that is used to design incentive-compatible contracts when moral hazard is present. Figure 1 illustrates the states of wealth for one agent under an individual insurance contract (Panel A) and under a group insurance scheme (Panel B). In the group scheme, the provision of self-protection effort essentially becomes a public good because one agent's decision to reduce the loss probability directly affects the expected payouts of the other agent, from which the agent cannot be excluded.

\footnotetext{
${ }^{5}$ Perfect observation of risk-taking, in general, is either impossible or prohibitively expensive (Holmström 1979; Shavell 1979; Arnott and Stiglitz 1991). Even if insurers are able to discriminate those who are providing self-protection effort from those who are not, insurance regulation often restricts discrimination due to ethical considerations such as in health insurance (Schmidt, Voigt, and Wikler 2010).

${ }^{6}$ Clarke (2011) considers a similar concept.
} 


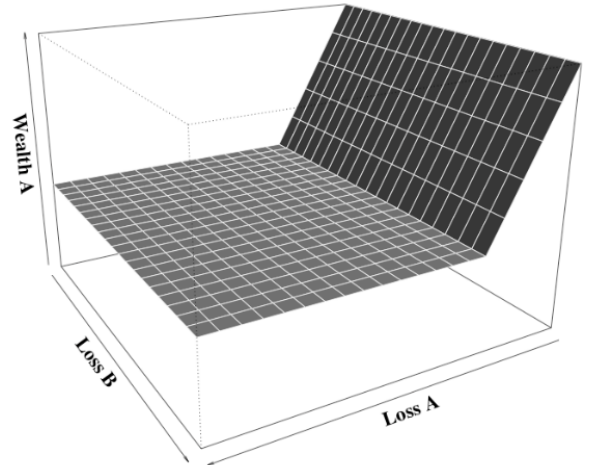

Panel B Group insurance

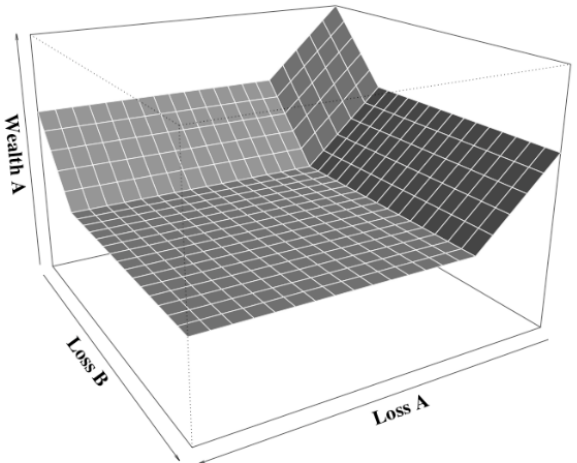

Figure 1. STATES OF WEALTH OF AGENT A CONTINGENT ON OWN AND AGENT B'S LOSS FOR INDIVIDUAL INSURANCE (PANEL A) AND GROUP INSURANCE (PANEL B)

Suppose again that partial insurance with a deductible $D=L-x$ is available at cost $c \cdot(L-D)$ but that the risk inherent in the deductible is shared between two agents in a group insurance policy. The four possible states of wealth are then $Y_{00}=W-e-c \cdot(L-D), Y_{01}=W-e-c \cdot(L-D)-$ $\frac{D}{2}, Y_{10}=W-e-c \cdot(L-D)-\frac{D}{2}$ and $Y_{11}=W-e-c \cdot(L-D)-D$, where $Y_{z}$ is the outcome under the different states of the world $z \in\{00,01,10,11\}$, with the first digit indicating the loss state of individual $i$ and the second digit indicating the loss state of individual $j$. It follows that $E U_{i}=$ $\sum_{z} p_{z}\left(e_{i}, e_{j}\right) U_{i}\left(Y_{z}\right)$, where $p_{z}$ is composed of $p_{i}\left(e_{i}\right)$ and $p_{j}\left(e_{j}\right)$. Using again the first-order condition as in Equation (2) and assuming full insurance (i.e., $D=0$ ), we obtain the same result as in the individual insurance case with $e_{i}^{*}=0$. The group insurance scheme with partial coverage, however, may generate lower optimal levels of self-protection effort $e^{*}$ than the equivalent individual insurance. Applying the first-order condition, we can see that the marginal utility gain from self-protection represented by the left-hand side of Equation (2) is lower for the group scheme than for individual insurance: ${ }^{7}$

$$
\text { (3) }-p^{\prime}\left(e_{i}\right)\left[\left(p_{j}\left(U\left(Y_{01}\right)-U\left(Y_{11}\right)\right)+\left(1-p_{j}\right)\left(U\left(Y_{00}\right)-U\left(Y_{10}\right)\right)\right]\right. \text {. }
$$

The reason for the reduced gain is that only half of the deductible will be saved in the loss case instead of the whole deductible in the individual insurance case. The exact utility gain depends on the shape of the utility function, but as a reference point, for risk-neutral individuals, it is half of the utility gain under individual insurance (as $Y_{01}=Y_{10}=\frac{Y_{11}+Y_{00}}{2}, Y_{11}=Y_{1}, Y_{00}=Y_{0}$ and $U^{\prime}($.) is constant). On the cost side, represented by the right-hand side of Equation (2), the change also depends on the shape of the utility function, but the direction of this change is less clear than in the individual insurance case:

$$
\text { (4) } \begin{aligned}
p_{i} p_{j} U^{\prime}\left(Y_{11}\right) & +p_{i}\left(1-p_{j}\right) U^{\prime}\left(Y_{10}\right)+\left(1-p_{i}\right) p_{j} U^{\prime}\left(Y_{01}\right) \\
& +\left(1-p_{i}\right)\left(1-p_{i}\right) U^{\prime}\left(Y_{00}\right)
\end{aligned}
$$

\footnotetext{
${ }^{7}$ We ignore beliefs about player $j$ 's self-protection decision from this point onwards, i.e., we treat the loss probability $p_{j}$ as given. We revisit this assumption and specifically discuss the role of beliefs at the end of this section.
} 
The group scheme shifts some of the weight from the marginal utilities at the extreme points $Y_{11}$ and $Y_{00}$ to their average of $Y_{01}=Y_{10}$. For risk-neutral individuals with constant marginal utility, this condition is irrelevant. For risk-averse or risk-loving individuals, however, there might be a change that depends, inter alia, on $U^{\prime \prime \prime}($.$) , i.e., prudence (Liu and Meyer 2012). It is thus possible that there is$ also a change in costs associated with the provision of self-protection effort under the group scheme, but such a change is less obvious and more sensitive to assumptions regarding the shape of the utility function. We show in later simulations that popular parametric specifications of the utility function clearly predict a decrease in self-protection effort. Intuitively, sharing the deductible works similarly to reducing the deductible in terms of not only its incentive effect but also its exposure to risk. It is straightforward to show that the negative effect of the group scheme also holds for groups of sizes of $n>2$, where each deductible would be divided by $n$. Again, as a reference point, the utility gain from self-protection effort for risk-neutral individuals would be the utility gain under individual insurance divided by $n$. As $n \rightarrow \infty$, the situation converges to a situation with full insurance such that the optimal self-protection effort decision converges to $e_{i}^{*}=0$.

\section{Optimal Effort under Group Insurance and Pro-social Preferences}

The remarkable aspect of the group scheme becomes obvious when we consider pro-social preferences as introduced by Rabin (1993), Fehr and Schmidt (1999), and Bolton and Ockenfels (2000), among others. The fundamental idea is that individuals are concerned not only with their own payoffs but also with the payoffs of other individuals or, more broadly, with a desire to "do the right thing" or to "make the moral" choice (Levitt and List 2007). The literature reveals a great willingness to contribute to public goods (Chaudhuri 2010) despite the individual incentive to free-ride on the contributions of others. In our setting, an individual's self-protection effort under the group scheme can be seen as a public good contribution because it decreases both group peers' loss probabilities. However, it is an open question whether pro-social concerns in joint liability groups are sufficient to stimulate significant cooperation in risky as opposed to deterministic settings and translate into higher social efficiency. Contributions could potentially be lower due to the stochastic nature of the public good (Berger and Hershey 1994; Gong, Baron, and Kunreuther 2009), but could also be compensated by the common identity induced by the group setting (Eckel and Grossmann 2005; Kramer and Brewer 1986).

Here, we assume that the pro-social individual $i$ in some positive way cares about the benefit of individual $j$ such that $\partial U_{i} / \partial Y_{j}>0:^{8}$

$$
\text { (5) } E U_{i}=\sum_{z} p_{z}\left(e_{i}, e_{j}\right) U_{i}\left(Y_{z, i}, Y_{z, j}\right) \text {. }
$$

\footnotetext{
${ }^{8}$ Apparently, $\partial U_{i} / \partial Y_{j}$ could also be smaller than 0 , for example, due to negative reciprocity or envy. For expositional reasons and because we believe that positive motivation is more likely to be relevant here, we present our theoretical intuition assuming $\partial U_{i} / \partial Y_{j}>0$. However, it is easy to go through the theory assuming the reverse.
} 
If we compare the marginal cost side of self-protection effort to the version without pro-social preferences, there is no obvious change in incentives; $e_{i}$ is still borne privately, and thus the utility costs depend on the partial derivative of the utility function with respect to $Y_{i}$, similar to Equation (4): ${ }^{9}$

$$
\begin{gathered}
p_{i} p_{j} U_{i}{ }^{\prime}\left(Y_{11, i}, Y_{11, j}\right)+p_{i}\left(1-p_{j}\right) U_{i}{ }^{\prime}\left(Y_{10, i}, Y_{10, j}\right) \\
+\left(1-p_{i}\right) p_{j} U_{i}{ }^{\prime}\left(Y_{01, i}, Y_{01, j}\right)+\left(1-p_{i}\right)\left(1-p_{i}\right) U_{i}{ }^{\prime}\left(Y_{00, i}, Y_{00, j}\right)^{\prime}
\end{gathered}
$$

where $U_{i}{ }^{\prime}(.,$.$) is the partial derivative w.r.t. Y_{i}$. The marginal benefit, however, now reads as follows:

$$
\text { (7) }-p^{\prime}\left(e_{i}\right)\left[\begin{array}{c}
p_{j}\left(U_{i}\left(Y_{01, i}, Y_{01, j}\right)-U_{i}\left(Y_{11, i}, Y_{11, j}\right)\right) \\
+\left(1-p_{j}\right)\left(U_{i}\left(Y_{00, i}, Y_{00, j}\right)-U_{i}\left(Y_{10, i}, Y_{10, j}\right)\right)
\end{array}\right] \text {. }
$$

This means that the marginal benefit still includes the benefit of increasing $Y_{i}$ but now further accounts for the increase in $Y_{j}$. For illustrational purposes, Equation (7) can be divided into one part containing the utility change caused by the increase in $Y_{i}$, similar to Equation (3), and an additional part containing the utility change through $Y_{j}$. Although there is now an obvious change in incentives, the exact change still depends on functional form assumptions. The general formulas nevertheless provide an intuition that the incentive to provide self-protection effort under the group scheme should increase with pro-social concerns. A benchmark example reads as follows: a risk-neutral individual $i$ without pro-social preferences $U_{i}\left(Y_{z, i}, Y_{z, j}\right)=Y_{z, i}$ has the same marginal costs but half the marginal benefit of self-protection effort when comparing the group to the individual scheme. Introducing prosocial concerns $\gamma$ such that $U_{i}\left(Y_{z, i}, Y_{z, j}\right)=Y_{z, i}+\gamma \cdot Y_{z, j}$, the marginal benefit increases with $\gamma$ until incentives are equivalent in the individual and the group scheme once $\gamma=1$.

When diverging from risk neutrality, the setting becomes more complicated because the marginal utility of wealth is not constant. Generally, modeling pro-social behavior in risky environments is not a standardized task, and there is no common approach to doing so. The existing modeling approaches for pro-social preferences are not designed for risky environments. Absolute utility is sensitive to scaling by risk-aversion parameters, and it is difficult to maintain a sensible weighting of player $j$ 's wealth when varying risk-aversion parameters. ${ }^{10} \mathrm{We}$ avoid the problem by restricting our attention to two alternative specifications in which $Y_{i}$ and $Y_{j}$ are subject to scaling by the same utility function $U_{i}($.$) , the details of which are discussed in online Appendix A.$

Thus far, we have not discussed the role of beliefs about self-protection effort of group peers, but these beliefs are important for at least two reasons. First, self-protection effort $e_{j}$ affects the probabil-

${ }^{9}$ Including a second dimension $Y_{j}$ in the utility function can have arbitrary shape effects such that the partial derivative with respect to $Y_{i}$ might change. However, the manipulation should preserve some properties of the self-interested utility function (such as approximate risk aversion) for a ceteris paribus comparison. One property-preserving manipulation would be to assume separability of the utility function such that individual $i$ acts like a self-interested agent whenever the outcome of individual $j$ cannot be influenced. In this case, the marginal costs of self-protection would be equivalent to the costs without pro-social preferences. Below, we will discuss different ways of modeling pro-social preferences in our setting. As a general remark, any specification of pro-social preferences that substantially increases the marginal costs of sacrificing income when caring about someone else would be quite counterintuitive, in our view.

${ }^{10}$ Fudenberg and Levine (2012) provide initial insights into the difficulties of jointly modeling risk and fairness preferences, and Saito (2013) contributes to the topic by generalizing the Fehr and Schmidt (1999) model of inequality aversion to risky situations. 
ity $p_{j}$ and $j$ 's wealth $Y_{z, j}$, which might change both the marginal costs and benefits of effort. For riskneutral individuals (i.e., constant marginal utility in $Y_{i}$ and $Y_{j}$ ) this does not play a role, but the absolute costs and benefits of self-protection effort change for all other types. The second reason is very important in our view. The literature on pro-social preferences recognizes reciprocity or conditional cooperation (Fischbacher, Gächter, and Fehr 2001) as a powerful driver of pro-social behavior. In case behavior of other individuals cannot be observed, this might imply the conditionality of prosociality on the expected fairness of others. This means, agent $i^{\text {'s }}$ beliefs about agent $j^{6}$ s selfprotection effort $\tilde{e}_{i}$ might drive the degree of pro-social concerns $\gamma$. Such dependence can easily be motivated by applying Rabin's (1993) fairness model to our setting (see online Appendix B). Alternatively, inequity aversion (Fehr and Schmidt 1999) might drive the desire of agents to provide the same level of effort as their group members. We therefore specifically elicit and analyze beliefs in our experiment.

\section{Experimental Design and Procedures}

\section{A. Effort Game}

We model the self-protection effort choice under different contractual settings in artifactual field and laboratory experiments. Risk is introduced in the form of a lottery that involves drawing one of ten balls (i.e., four orange, six white) from an opaque bag. Orange balls represent a loss $(L)$; white balls indicate no loss. Every participant is provided with an initial endowment $W$. This design is incentive-compatible (Cummings, Harrison, and Rutström 1995) and incorporates the prospect of losing money instead of winning money as stressed by, for example, Harrison and Rutström (2008). The payoff of participants thus is $W$ with $p=0.6$ and $W-L$ with $p=0.4$. Self-protection is simulated by exchanging a bag with four orange and six white balls for one with only two orange balls and eight white balls against an effort cost of $e$. The payoff of participants when using this option is $W-e$ with $p=0.8$ and $W-e-L$ with $p=0.2$. We use an initial endowment of $W=300$, a loss of $L=200$, and a cost of self-protection of $e=20$. Whereas for the Philippine field laboratory setting the laboratory currency is exchangeable to real Philippine pesos (PHP) at a rate of 1:1, the laboratory currency for the German computer laboratory setting is exchangeable to real Euro (EUR) at a rate of 20:1. In addition, participants received a show-up fee of PHP 50 (EUR 0.9) in the Philippines and EUR 4 in Germany. ${ }^{11}$

${ }^{11}$ For the Philippine sample, the initial endowment of PHP 300 (approximately EUR 5.2 using the exchange rate of early October 2013) is above the minimum daily wage of PHP 250 in the agricultural sector in the Iloilo province as of October 2013 (Republic of the Philippines 2013) and well above the average daily income of participants. For the German student sample, the initial endowment of EUR 15 corresponds to about 70 percent of participants' daily income. 


\section{B. Treatments}

Every participant played the basic effort game as presented in Section III.A over three rounds and is randomly assigned to one of four insurance treatments or the control treatment for the subsequent rounds four through six. Insurance uptake was mandatory in all treatments. Those assigned to the control treatment $C$ again played the basic effort game in rounds four through six. A comprehensive overview of all treatments is presented in Table 1.

TABLE 1 -EXPERIMENTAL TREATMENT PLAN

\begin{tabular}{|c|c|c|c|c|c|}
\hline \multicolumn{6}{|c|}{ Panel A: Universal parameters } \\
\hline Initial endowment & \multicolumn{5}{|c|}{300} \\
\hline Loss & \multicolumn{5}{|c|}{200} \\
\hline Self-protection effort cost & \multicolumn{5}{|c|}{20} \\
\hline Loss probability ex self-protection effort & \multicolumn{5}{|c|}{0.40} \\
\hline Loss probability cum self-protection effort & \multicolumn{5}{|c|}{0.20} \\
\hline \multicolumn{6}{|c|}{ Panel B: Treatment characteristics } \\
\hline & & \multicolumn{2}{|c|}{ Individual insurance } & \multicolumn{2}{|c|}{ Group insurance } \\
\hline & $\mathrm{C}$ & $\mathrm{I}_{\text {low }}$ & $\mathrm{I}_{\text {high }}$ & $\mathrm{G}_{\text {private }}$ & $\mathrm{G}_{\text {public }}$ \\
\hline \multicolumn{6}{|c|}{ Panel B.1: Treatment-specific parameters } \\
\hline Deductible & - & 100 & 40 & 100 & 100 \\
\hline Premium & - & 50 & 80 & 50 & 50 \\
\hline Self-protection effort observable & No & No & No & No & Yes \\
\hline \multicolumn{6}{|c|}{ Panel B.2: Expected value (EV) and standard deviation (SD) change from self-protection effort } \\
\hline EV change from self-protection effort & +20 & 0 & -12 & \multirow{2}{*}{\multicolumn{2}{|c|}{$\begin{array}{r}-10 \\
-4^{\mathrm{a}}\end{array}$}} \\
\hline SD change from self-protection effort & -18 & -9 & -4 & & \\
\hline \multicolumn{6}{|c|}{ Panel B.3: Treatment sequence } \\
\hline Rounds 1 to 3 & $\mathrm{C}$ & $\mathrm{C}$ & $\mathrm{C}$ & $\mathrm{C}$ & $\mathrm{C}$ \\
\hline Rounds 4 to 6 & $\mathrm{C}$ & $\mathrm{I}_{\text {low }}$ & $\mathrm{I}_{\text {high }}$ & $\mathrm{G}_{\text {private }}$ & $\mathrm{G}_{\text {public }}$ \\
\hline \multicolumn{6}{|c|}{ Panel B.4: Participants and sessions } \\
\hline Number of participants (Philippines) & 175 & 176 & 175 & 288 & 178 \\
\hline Number of participants (Germany) & 147 & 149 & 147 & 151 & 106 \\
\hline Number of sessions (Philippines) & 22 & 22 & 22 & 36 & 22 \\
\hline Number of sessions (Germany) & 37 & 35 & 37 & 20 & 16 \\
\hline
\end{tabular}

Notes: All values are presented either in PHP (i.e., Philippine sample) or laboratory currency (i.e., German sample), exchangeable to Euro with an exchange rate of 20:1. " The standard deviation under group insurance depends on both agents' decisions, and we show standard deviation under the assumption that the group peer provides self-protection effort. If the group peer does not provide self-protection effort, the decrease in standard deviation from self-protection is slightly lower at 3 .

The insurance treatments were divided into two primary treatments: the individual insurance $(I)$, and the group insurance $(G)$. Both primary treatments again included two sub-manipulations. For the individual insurance treatment, we varied the deductible $D$. $I_{\text {low }}$ had a high deductible of 100 (i.e., low coverage), and $I_{\text {high }}$ had a low deductible of 40 (i.e., high coverage). The rationale for varying the level of coverage was to vary the economic incentive to provide self-protection effort, which is essentially what insurance does. Whereas self-protection effort under the low coverage policy has an expected value of zero, under the high coverage policy, effort provision is unattractive for most rational individuals because it has a negative expected value (see Panel B.2 of Table 1).

The group insurance treatment $G$ differed from the individual insurance $I_{l o w}$ in that this type of insurance covered groups of two and in that losses below the deductible were shared within the group. ${ }^{12}$ Although the deductible and premium are equal to $I_{\text {low }}$, group insurance effectively provides

${ }^{12}$ Behavior in our group insurance scheme may be susceptible to the size of the group. Although restricting the group size to two individuals maximizes the number of observations in our experimental setup, it raises questions regarding the robustness with increasing group size. While we did not test for the effect of group size in our setup, experimental evidence from microfinance indicates that cooperation in groups with joint liability is relatively robust to a variation in group size (Abbink, Irlenbusch, and Renner 2006). We randomly varied "network strength" in the Philippine sample. Strong networks consisted of the originally invited player and the accompanying peer. Weak groups were formed by randomly assigning an originally invited person to another participant. This variation was implemented within a session - that is, there would usually be two strong and two weak groups in each $G_{\text {private }}$ session. This approach decreased the number of 
more risk protection because the risk inherent in the deductible is shared within the group. This renders self-protection unattractive for most self-interested rational individuals because it has a negative expected value (see Panel B.2 of Table 1). Treatment $G_{\text {private }}$ implemented group insurance with selfprotection as private information, making it impossible for group members to infer the level of their peers' risk-taking. In $G_{p u b l i c}$, we revealed the self-protection decision within the group at the end of a round. The latter treatment was included because it might introduce strategic concerns. Observing effort provision allows identification and punishment of "free-riders" who do not provide selfprotection effort (compare discussion in Section V.C),

To calibrate the monetary values in our experiment, we ensured that the premiums were related to the expected value of claims and thus reflected the differences in deductibles. Because the actual price of an insurance policy is its loading, we added a 25 percent markup to all insurance treatments. The insurer's inability to observe self-protection in our experimental setting resembled real-world scenarios in that insurers usually are not able to detect such behavior at reasonable cost. The effort cost for self-protection $e=20$ was chosen such that it would be economically beneficial to provide self-protection effort while having no insurance even for risk-neutral and some risk-loving subjects.

\section{Recruitment, Treatment Allocation, and Procedures}

Field Laboratory Philippines.-The experiment was conducted with 992 rural villagers from the Iloilo and Guimaras provinces of the Philippines in October and November 2013. We applied a twostage randomization schedule, first by randomly sampling villages and then by selecting participants for the selected villages in the second stage. ${ }^{13}$ Sixteen households were randomly chosen from within a village using complete household lists to which we had unrestricted access. Each invitation had one additional letter for a friend or relative of the invitee's choice attached, such that in total 32 distinct households were invited in each village. ${ }^{14}$ We incentivized households to send the household head by awarding an additional PHP 20 (EUR 0.3) to the final payouts in the event of this person's participation; however, spouses were also eligible to participate. We also required participants to be between 18 and 65 years of age.

The allocation of treatments to specific villages was determined randomly; however, we designed clusters of villages that were similar in terms of experiment timing, village size, wealth, and remoteness. Within each of these clusters the distribution of treatments was balanced. ${ }^{15}$ Different treatments required distinct instructions and thus were played in a different session. We always played

observations per session for one treatment. To keep the number of individual observations in each variant similar to the other treatments, we conducted more sessions in the cases of treatments $G_{\text {private }}$.

${ }^{13}$ Permission to conduct the research was obtained in advance from the elected village representative (i.e., the Punong Barangay) for all villages. The pool of villages was restricted to rural villages only and excluded relatively affluent areas, i.e., the first two out of five income classes according to the definitions of the Philippine Statistics Authority (Republic of the Philippines 2014).

${ }^{14}$ Observing two clearly linked peers allowed us to manipulate network strength within groups. Half of the groups were composed of close peers, the other half of random participants (compare analysis in Section V.D).

${ }^{15}$ This approach minimizes the Mahalanobis distance of the average village from its cluster average, normalizing the variables using the covariance matrix. The exact calculation and assignment procedure are available upon request. Balancing with respect to timing of the experiment became especially relevant after Typhoon Haiyan hit the province of Iloilo in November 2013 after 67 of 124 sessions had been conducted. 
four sessions with distinct treatments per village to further reduce the likelihood of correlation between village-specific characteristics and treatment assignment. In total we conducted 124 sessions.

Each participant first played three rounds without insurance and then another three rounds depending on the treatment assignment. Only one of the rounds was paid out at random. At the end of each round, subjects were informed about their result and the initial endowment was restored for the next round. We used play money throughout the experiment to represent the amounts at stake and the payoff of only one round was paid out in real money. ${ }^{16}$ We explained the approximate duration, number of rounds, and payout mechanism to all participants in advance. Before and after the experiment, we administered face-to-face questionnaires to assess the participants' sociodemographic characteristics along with more complex issues such as numeracy and risk aversion.

The experimental procedure for one session round was as follows. First, the instructor explained the experiment to all participants jointly and each participant received an initial endowment for one round. After the introduction, each participant individually answered test questions to demonstrate his or her understanding of the experiment. Only when all questions were answered correctly was the participant allowed to continue. The participants were then given the choice between two opaque bags, one with four and one with two orange balls; choosing the latter bag with a reduced loss probability required a payment. Prior to their choice, we elicited beliefs about the self-protection decision of their respective group peer in the group treatments. Even though the group members were not anonymous, they were not allowed to communicate. ${ }^{17}$ After the participants made their choice, they drew from the chosen bag to determine their state (i.e., loss or no loss). The result from that round was recorded, and the participant was sent back to his or her seat. In the case of group insurance, the result from one round could be calculated only after both parties to the group insurance contract had determined their losses; thus, these treatments included an additional step.

Computer Laboratory Germany.-The experimental procedures in the German computer laboratory setting mimicked those implemented in the Philippine field laboratory. The main difference was the interaction with a computer terminal as opposed to an experimenter. We conducted the experiments in the experimental laboratories of the University of Mannheim and the University of Magdeburg using the experimental software z-Tree (Fischbacher 2007) in March and April 2015. Experimental treatments were randomized within each session. Participants were recruited through the subject pools of the respective experimental laboratories, and participants were required to have a good command of the German language. We conducted the experiment with 700 participants (i.e., 180 from Mannheim and 520 from Magdeburg) in 37 sessions. ${ }^{18}$ One notable difference from the Philippine field laboratory resulting from the computer laboratory setting was that players were not able to iden-

\footnotetext{
${ }^{16}$ The show-up fee was paid even if participants were not able or willing to complete the entire procedure. We made it very clear that all participants could discontinue the experiment at any time; however, there were no dropouts.

${ }^{17}$ Together with not revealing the choice of bags this should ensure that strategic considerations have no influence on self-protection decisions. Only when making this information public should strategic motives play a role.

${ }^{18}$ In the German sample, observations of 1 round for 24 subjects (i.e., evenly distributed between treatments) were lost due to a technical problem in the laboratory.
} 
tify their group peers under the group insurance treatments in the German computer laboratory; however, they were informed that their peer was one of the session's participants.

\section{Research Questions and Hypotheses}

Our experimental design permits investigation of two main research questions. The first is whether effort provision (i.e., self-protection) decreases when making the payoff of agents less statedependent (i.e., increasing insurance coverage) under an individual contract. Such classical moral hazard behavior finds empirical confirmation in a large literature and is economically rational (Pauly 1974) because wealth becomes less dependent on ex-ante risk taking. The existence of moral hazard is a precondition for the relevance of the subsequent question. In particular, we investigate whether a group contract can induce efficiency improvements in the tradeoff between individual risk exposure and self-protection effort provision compared to the individual contract and under which conditions this may hold true.

To derive our hypotheses, we predict the share of individuals providing self-protection effort under each treatment based on simulations of our theory. The idea is that the self-protection decision is a risky choice and hence governed by risk aversion. We consider the valuation of choices by a von Neumann-Morgenstern utility function with constant relative risk aversion (CRRA). When using parametric specifications of these utility functions, we introduce three archetypes of pro-social behavior along the continuum of possible behavioral types in our framework for pro-social preferences. The first archetype is purely self-interested $(\gamma=0)$. The second type weights one's own payoff and the payoff of the group peer equally $(\gamma=1)$. The third type also fully accounts for payoffs of group peers $(\gamma=1)$ but additionally adapts risk taking consistent with the recent literature on risk taking on behalf of others (e.g., Andersson et al. 2013; 2016). Further details are provided in online Appendix A.

\begin{tabular}{|c|c|c|c|c|c|c|}
\hline Treatment & $\mathrm{C}$ & $\mathrm{I}_{\text {low }}$ & $I_{\text {high }}$ & \multicolumn{3}{|c|}{$\mathrm{G}$} \\
\hline \multicolumn{7}{|c|}{ Preference concept } \\
\hline Pro-social & No & No & No & $\mathrm{No}^{\mathrm{a}}$ & $\mathrm{Yes}^{\mathrm{a}}$ & $\mathrm{Yes}^{\mathrm{a}}$ \\
\hline$\gamma$ & - & - & - & 0 & 1 & 1 \\
\hline$\rho$ & - & - & - & keep & keep & adapt \\
\hline \multicolumn{7}{|c|}{ Panel A: Risk-aversion parameter $\rho$ domain for which self-protection effort is preferred } \\
\hline & {$\left[\begin{array}{llll}3 & 1 & 3 & 0\end{array}\right.$} & & & $\mathrm{A}: \varnothing$ & A: $[0.0,8.3]$ & A: $[-0.6,16.0]$ \\
\hline Philıppınes & \multirow{3}{*}[-3.1,3.9]{} & {$[0.0,4.0]$} & $\emptyset$ & B: $\varnothing$ & B: $[0.0,8.5]$ & B: $[-0.6,16.4]$ \\
\hline \multirow{2}{*}{ Germany } & & \multirow{2}{*}[0.0,4.0]{} & \multirow{2}{*}{$\emptyset$} & A: $\varnothing$ & A: $[0.0,8.3]$ & $\mathrm{A}:[-1.2,14.2]$ \\
\hline & & & & $\mathrm{B}: \emptyset$ & B: $[0.0,8.5]$ & B: $[-1.9,14.8]$ \\
\hline \multicolumn{7}{|c|}{ Panel B: Share of population for which self-protection effort is preferred } \\
\hline Philippines & 0.82 & 0.64 & 0 & 0 & A/B: 0.71 & A/B: 0.93 \\
\hline Germany & 0.85 & 0.81 & 0 & 0 & A/B: 0.91 & A/B: 0.98 \\
\hline
\end{tabular}

Notes: Simulations procedures using CRRA expected utility of the functional form $\mathrm{U}(Y)=Y^{(1-\rho)}$ for Y $>0$ with risk-aversion parameter $\rho$

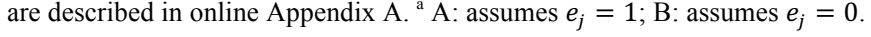

Panel A of Table 2 shows the risk-aversion parameter domain for which individuals are expected to provide self-protection effort in our experimental setting. We predict the share of individuals providing self-protection effort in Panel B utilizing data from Binswanger (1980) lottery choices, 
which allow estimation of the distribution of risk-aversion parameters of our sample (see online Appendix C). ${ }^{19}$ Predicted parameter ranges and population shares are shown for all treatments.

Hypothesis 1.-We expect that making payoffs of agents less state-dependent (i.e., increasing insurance coverage) will decrease the likelihood of providing self-protection effort under the individual scheme $(H 1)$. In line with moral hazard, our simulations clearly predict a decreasing share of selfprotection decisions when increasing insurance coverage. While the provision of individual insurance with low coverage should decrease self-protection effort only slightly, effort levels should drop to zero with high coverage.

Hypothesis 2.-The theoretical intuition we provide in Section II suggests that a joint liability group scheme can lead to efficiency improvements if individuals exhibit pro-social preferences. We therefore expect that the group scheme will induce efficiency improvements in the tradeoff between individual risk exposure and self-protection effort provision compared to the individual insurance schemes (H2). There are two focal comparisons that illustrate a potential efficiency gain. The first focal point of comparison is the low-coverage individual scheme. The reason is that if the group contract is able to attain similar-or even higher-levels of self-protection, there is a clear efficiency gain: at equal costs (i.e., premium payment) and levels of self-protection the group contract leaves substantially lower risk for the individual. Assuming high levels of pro-sociality, we expect that the likelihood of providing self-protection effort under the group contract is at least equal compared with the low-coverage individual insurance $(H 2 a)$.

The second focal point of comparison is the high-coverage individual scheme. The reason is that the group and the high-coverage individual contract exhibit similar economic incentives to provide self-protection effort for self-interested agents (residual idiosyncratic risk is similar and predicted selfprotection effort is zero in both cases). Assuming sufficient levels of pro-sociality exist, though, we expect that the likelihood of providing self-protection effort under the group contract is higher compared with the high-coverage individual insurance $(H 2 b)$.

Our discussion about reciprocity and conditional cooperation as important drivers of pro-social behavior in Section II.D suggests that pro-social motives should be stronger with positive beliefs about the other group member. Thus, we expect that those individuals with positive beliefs about the self-protection effort provision of the group peer are more likely to provide self-protection effort in the group scheme than those individuals with negative beliefs (H3). Hence, especially those individuals with positive beliefs should behave in line with hypotheses $H 2 a$ and $H 2 b$. In contrast to the first two hypotheses, $H 3$ cannot be tested by comparing experimental treatment arms, but only through a comparison of participants within the group scheme.

\footnotetext{
${ }^{19}$ There is a multitude of approaches to eliciting risk preferences, such as the multiple price list (Miller, Meyer, and Lanzetta 1969; Holt and Laury 2002) and the certainty equivalent approach (Becker, Degroot, Marschak 1964). We opted for the ordered lottery selection method because it is readily understandable and, in particular, has been previously used in a low-income developing country setting (Cole et al. 2013). For the German sample, we additionally applied the multiple price list design as in Holt and Laury (2002). The resulting predictions regarding the share of the population for which self-protection is preferred are $1(C), 0.77\left(I_{\text {low }}\right), 0\left(I_{\text {high }}\right), 0(G), 0.77\left(G_{\text {keep } \rho}\right)$ and 0.94 $\left(G_{\text {adapt } \rho}\right)$, thus establishing similar predictions.
} 


\section{Experimental Results}

\section{A. Descriptive statistics}

Descriptive statistics of the sample characteristics are presented in Table 3. Most of the participants in the Philippine sample were female, but in the German sample the gender mix is more balanced. In the Philippines we wanted to make sure that the sample is representative for members of the household, who are involved in financial decision-making on the household level, which holds true for almost all of our participants. ${ }^{20}$ Attrition would have been a relevant factor if we had insisted on males. To assess whether our results are sensitive to the gender imbalance, we also conduct separate analyses for female and male participants in the Philippine sample. Table F1 in online Appendix F shows that the main results are similar across gender. In fact, none of the coefficients is significantly different across the two subsamples.

The average age in the Philippine sample is slightly under 40. Because the German sample was recruited from a student population, the average age of approximately 23 is lower. With respect to the households' financial situations, the average annual household income in the Philippine sample is approximately PHP 85,000 (EUR 1,466). The average income of wage earners in the sample is below the minimum daily wage in the Iloilo province (Republic of the Philippines 2013). Thus, our Philippine sample represents a typical low-income population, while our German student sample represents a typical well-educated and higher-income population with an average income of EUR 7,719.

Due to the randomized allocation of treatments, we expect all characteristics to be balanced between the treatments and the control group. Applying multivariate balancing tests accounting for correlations between the treatments and multiple variables, we cannot reject the hypothesis that characteristics have the same average across treatments. Thus, the participants' characteristics are balanced between the treatments and the control group for both the Philippine and the German samples.

\footnotetext{
${ }^{20}$ Our results on spouses' financial responsibility match those observed by Ashraf (2009), who finds that in 80 percent of the households surveyed in her Philippine study, the wife holds the income and does the budgeting and also makes the major financial decisions in 49 percent of households.
} 
TABLE 3-SUMMARY STATISTICS AND BALANCING CHECKS

\begin{tabular}{|c|c|c|c|c|c|c|c|c|c|c|c|c|}
\hline \multirow[b]{2}{*}{ Variable } & \multicolumn{6}{|c|}{ Philippine sample } & \multicolumn{6}{|c|}{ German sample } \\
\hline & C & $\mathbf{I}_{\text {low }}$ & $\begin{array}{c}\mathbf{I}_{\mathbf{h i g h}} \\
\quad \text { Mean }^{a} \\
\text { (Standard er }^{\text {Stand }}\end{array}$ & $\begin{array}{l}\mathbf{G}_{\text {private }} \\
\text { ror) }\end{array}$ & $\mathbf{G}_{\text {public }}$ & $\begin{array}{l}\text { Equality of } \\
\text { means }(p-v a l u e)^{f}\end{array}$ & $\mathbf{C}$ & $\mathbf{I}_{\text {low }}$ & $\begin{array}{l}\mathbf{I}_{\text {high }} \\
\text { Mean }^{a} \\
\text { andard err }\end{array}$ & $\mathbf{G}_{\text {private }}$ & $\mathbf{G}_{\text {public }}$ & $\begin{array}{l}\text { Equality of } \\
\text { means (p-value) }\end{array}$ \\
\hline \multicolumn{13}{|c|}{ Panel A: Sociodemographic characteristics } \\
\hline $\operatorname{Sex}(1=$ female $)$ & $\begin{array}{l}0.869 \\
(0.0279)\end{array}$ & $\begin{array}{l}0.818 \\
(0.0383)\end{array}$ & $\begin{array}{l}0.829 \\
(0.0354)\end{array}$ & $\begin{array}{l}0.868 \\
(0.0222)\end{array}$ & $\begin{array}{l}0.848 \\
(0.0329)\end{array}$ & 0.688 & $\begin{array}{l}0.435 \\
(0.041)\end{array}$ & $\begin{array}{l}0.53 \\
(0.041)\end{array}$ & $\begin{array}{l}0.415 \\
(0.408)\end{array}$ & $\begin{array}{l}0.437 \\
(0.0405)\end{array}$ & $\begin{array}{l}0.415 \\
(0.0481)\end{array}$ & 0.254 \\
\hline Age (in years) & $\begin{array}{l}38.0487 \\
(0.921)\end{array}$ & $\begin{array}{l}38.0568 \\
(1.0256)\end{array}$ & $\begin{array}{l}37.488 \\
(0.661)\end{array}$ & $\begin{array}{l}39.729 \\
(0.601)\end{array}$ & $\begin{array}{l}38.839 \\
(0.959)\end{array}$ & 0.263 & $\begin{array}{l}23.755 \\
(0.0338)\end{array}$ & $\begin{array}{l}23.195 \\
(0.292)\end{array}$ & $\begin{array}{l}23.463 \\
(0.326)\end{array}$ & $\begin{array}{l}23.166 \\
(0.272)\end{array}$ & $\begin{array}{l}23.481 \\
(0.254)\end{array}$ & 0.618 \\
\hline Financial responsibility ${ }^{\mathrm{b}}$ & $\begin{array}{l}0.972 \\
(0.0114)\end{array}$ & $\begin{array}{l}0.972 \\
(0.0114)\end{array}$ & $\begin{array}{l}0.988 \\
(0.00842)\end{array}$ & $\begin{array}{l}0.969 \\
(0.00915)\end{array}$ & $\begin{array}{l}0.966 \\
(0.0147)\end{array}$ & 0.697 & $\begin{array}{l}0.544 \\
(0.0412)\end{array}$ & $\begin{array}{l}0.503 \\
(0.0411)\end{array}$ & $\begin{array}{l}0.469 \\
(0.413)\end{array}$ & $\begin{array}{l}0.556 \\
(0.0406)\end{array}$ & $\begin{array}{l}0.462 \\
(0.0487)\end{array}$ & 0.415 \\
\hline $\begin{array}{l}\text { Annual income }{ }^{\mathrm{c}} \\
\text { (in } 1,000 \text { PHP or EUR) }\end{array}$ & $\begin{array}{l}74.867 \\
(7.279)\end{array}$ & $\begin{array}{l}65.236 \\
(5.779) \\
\end{array}$ & $\begin{array}{l}90.588 \\
(19.888)\end{array}$ & $\begin{array}{l}89.449 \\
(10.176)\end{array}$ & $\begin{array}{l}96.241 \\
(30.178)\end{array}$ & 0.683 & $\begin{array}{l}7.426 \\
(0.367) \\
\end{array}$ & $\begin{array}{l}7.968 \\
(0.306)\end{array}$ & $\begin{array}{l}7.908 \\
(0.386)\end{array}$ & $\begin{array}{l}7.636 \\
(0.259) \\
\end{array}$ & $\begin{array}{l}7.628 \\
(0.271) \\
\end{array}$ & 0.749 \\
\hline $\begin{array}{l}\text { Numeracy performance } \\
\text { (percent correct) }\end{array}$ & $\begin{array}{l}0.480 \\
(0.0152)\end{array}$ & $\begin{array}{l}0.466 \\
(0.0132)\end{array}$ & $\begin{array}{l}0.483 \\
(0.0138)\end{array}$ & $\begin{array}{l}\quad \text { Panel } \\
0.493 \\
(0.00859)\end{array}$ & $\begin{array}{l}\text { B: Numera } \\
0.461 \\
(0.0146)\end{array}$ & $\begin{array}{l}\text {, risk and ambiguity } \\
0.325\end{array}$ & $\begin{array}{l}\text { sion } \\
0.804 \\
(0.169)\end{array}$ & $\begin{array}{l}0.825 \\
(0.0158)\end{array}$ & 0.807 & 0.765 & 0.787 & 0.166 \\
\hline Ambiguity aversion ${ }^{\mathrm{d}}$ & $\begin{array}{l}(0.0172) \\
6.347 \\
(0.0747)\end{array}$ & $\begin{array}{l}0.013 \\
6.243 \\
(0.0648)\end{array}$ & $\begin{array}{l}(0.0103 \\
6.403 \\
(0.0737)\end{array}$ & $\begin{array}{l}6.028 \\
(0.059)\end{array}$ & $\begin{array}{l}(0.0140) \\
6.388 \\
(0.0705)\end{array}$ & 0.347 & $\begin{array}{l}(0.169) \\
5.290 \\
(0.0756)\end{array}$ & $\begin{array}{l}(0.0158) \\
5.404 \\
(0.0693)\end{array}$ & $\begin{array}{l}(0.01 / 3) \\
5.339 \\
(0.0763)\end{array}$ & $\begin{array}{l}(0.0194) \\
5.368 \\
(0.0831)\end{array}$ & $\begin{array}{l}(0.0208) \\
5.436 \\
(0.0810)\end{array}$ & 0.733 \\
\hline Risk aversion $^{\mathrm{e}}$ & $\begin{array}{l}3.838 \\
(0.159)\end{array}$ & $\begin{array}{l}3.716 \\
(0.121)\end{array}$ & $\begin{array}{l}3.745 \\
(0.135)\end{array}$ & $\begin{array}{l}3.642 \\
(0.113)\end{array}$ & $\begin{array}{l}3.883 \\
(0.149)\end{array}$ & 0.692 & $\begin{array}{l}3.163 \\
(0.108)\end{array}$ & $\begin{array}{l}3.0134 \\
(0.994)\end{array}$ & $\begin{array}{l}3.259 \\
(0.946)\end{array}$ & $\begin{array}{l}3.066 \\
(0.0961)\end{array}$ & $\begin{array}{l}3.085 \\
(0.125)\end{array}$ & 0.467 \\
\hline Equality of means (p-value) ${ }^{\mathrm{f}}$ & & 0.834 & 0.802 & 0.567 & 0.972 & 0.729 & & 0.106 & 0.663 & 0.445 & 0.596 & 0.424 \\
\hline Number of participants & 175 & 176 & 175 & 288 & 178 & & 147 & 149 & 147 & 151 & 106 & \\
\hline
\end{tabular}

Notes: Consistent with treatment assignment, all standard errors and tests are based on session averages in the Philippines sample and on the individual level in the German sample. ${ }^{\text {a }}$ Asterisks indicate the significance levels of the differences in means relative to the control group $C$ based on standard errors, which are reported in parentheses. ${ }^{b}$ Indicator variable in which 1 indicates responsibility for financial decisionmaking in the household. ${ }^{\mathrm{C}}$ Consistent with the relevant local concept we asked for household income in the Philippines and for individual income in the German student sample. ${ }^{\mathrm{d}}$ Scores are based on multiple seven-point Likert scale questionnaire items, where 7.00 indicates strong accordance; e.g., a score of 7.00 (1.00) indicates high (low) ambiguity aversion. ${ }^{e}$ We used the approach introduced by Binswanger (1980) in the form of the Barr and Genicot (2008) implementation; details are presented in online Appendix C. ${ }^{\mathrm{r}}$ We report p-values for multivariate equality in means tests based on Wilks's lambda test statistics. Whereas the column p-values provide test results for equality of means of one variable across all treatments, the row p-values indicate test results for equality of means of all variables between the respective treatment and the control group.

${ }^{* * *}$ Significant at the 1 percent level.

Significant at the 5 percent lever.

"Significant at the 10 percent level. 


\section{B. Main Results}

We show average self-protection across treatments in Figures 2, and 3. Online Appendix Table D1 mirrors these figures using estimates from linear probability models and shows that the results are robust to the inclusion of control variables. In all our analyses, we account for potential correlation within our unit of randomization (i.e., the experimental session for the Philippine sample and the individual for the German sample) via clustered standard errors. ${ }^{22}$ The results are shown separately for each of the two experimental settings: the Philippine field laboratory and the German computer laboratory.

Hypothesis 1.-To test for the fundamental effect of insurance coverage on self-protection $(\mathrm{Hl})$, we compare treatments $I_{\text {low }}$ and $I_{\text {high }}$ to the control treatment $C$ in Figure 2. In line with our predictions, the average probability of an individual to provide self-protection effort decreases with increasing levels of insurance coverage. In the sample from the Philippines, the reduction is 3 percentage points ( $p=0.454)$ under the low-coverage individual contract $I_{\text {low }}$ and 11.8 percentage points $(p=0.0289)$ under the high-coverage contract $I_{\text {high }}$. The effects are even more pronounced in the German sample, where the decrease is 20.6 percentage points $(p=0.000)$ under the low-coverage individual contract $I_{\text {low }}$ and 48.8 percentage points $(p=0.000)$ under the high-coverage contract $I_{\text {high }}$. This is a strong indication of moral hazard as expected under $H 1$. The effects are robust to the inclusion of covariates such as sex, age, income, intellectual capabilities, and risk and ambiguity aversion. Contrasting the results of the two sample populations shows that the effects are significantly higher in the German sample ( $p=0.000$ for $I_{\text {high }}$ and $p=0.0017$ for $\left.I_{\text {low }}\right)^{23}$

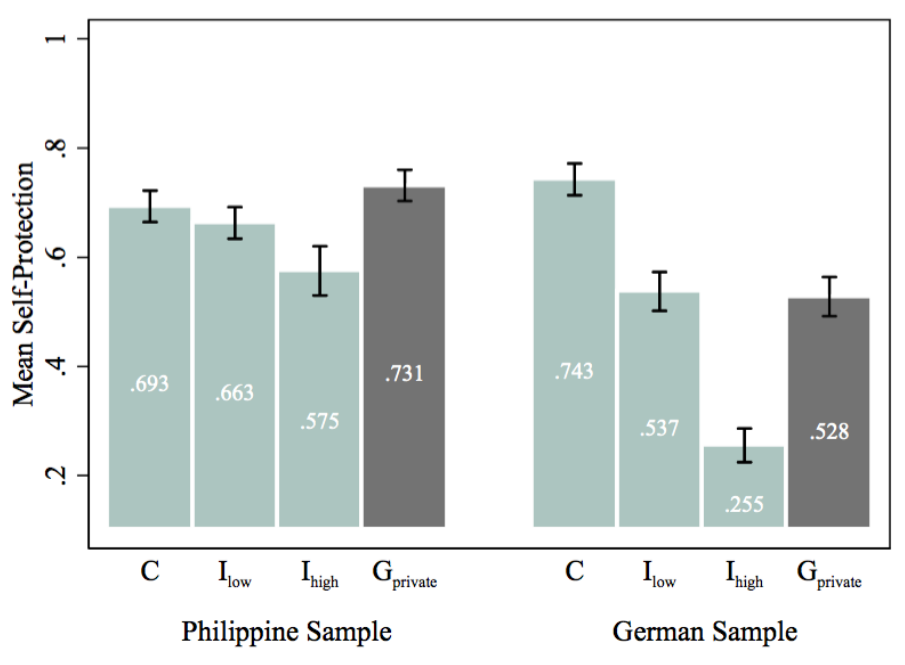

FIGURE 2. MEAN SELF-PROTECTION EFFORT BY SAMPLE

Notes: The bars represent the mean proportion of individuals choosing self-protection for the different treatment groups. Error bars indicate standard errors of the mean.

\footnotetext{
${ }^{22}$ We also applied individual-level clusters to the Philippine sample, resulting in smaller standard errors; however, we used the more conservative session-level clustering to maintain consistency with our assumptions in the sample balancing checks (see Section V.A). The results from an alternative probit model estimation are presented in online Appendix Table D2.

${ }^{23}$ To test for differences between regression coefficients resulting from the Philippine and the German sample populations, we estimated seemingly unrelated regressions (SUR) and Wald test statistics.
} 
Hypothesis 2.-We assess average efficiency gains of the group contract first by contrasting selfprotection under the group contract $G_{\text {private }}$ and the low-coverage individual contract $I_{\text {low }}$ (see Figure 2). We find that the group scheme induces an increase in self-protection of 6.8 percentage points relative to $I_{\text {low }}(p=0.0933)$ for the Philippine sample. For the German sample we find similar self-protection probabilities under $G_{\text {private }}$ and $I_{\text {low }}(p=0.852)$. These results imply efficiency gains as hypothesized under $H 2 a$, as in both cases the group scheme does not decrease probabilities to provide selfprotection compared to $I_{\text {low }}$ but achieves higher risk-protection at the same premium. The second focal point of comparison is the high-coverage individual scheme $I_{\text {high }}$. We find that the group scheme induces an increase in self-protection of 15.6 percentage points in the Philippine sample $(p=0.0041)$ and an increase in self-protection of 27.3 percentage points in the German sample $(p=0.000)$ relative to $I_{\text {high }}$. Materially higher levels of self-protection effort observed under the group scheme for both samples indicate a reduction in moral hazard given similar economic incentives to provide selfprotection effort as hypothesized under $H 2 b$. In summary, our results lend strong support to the hypothesized average efficiency gains induced by the group contract in the tradeoff between individual risk exposure and self-protection effort provision $(\mathrm{H} 2)$.

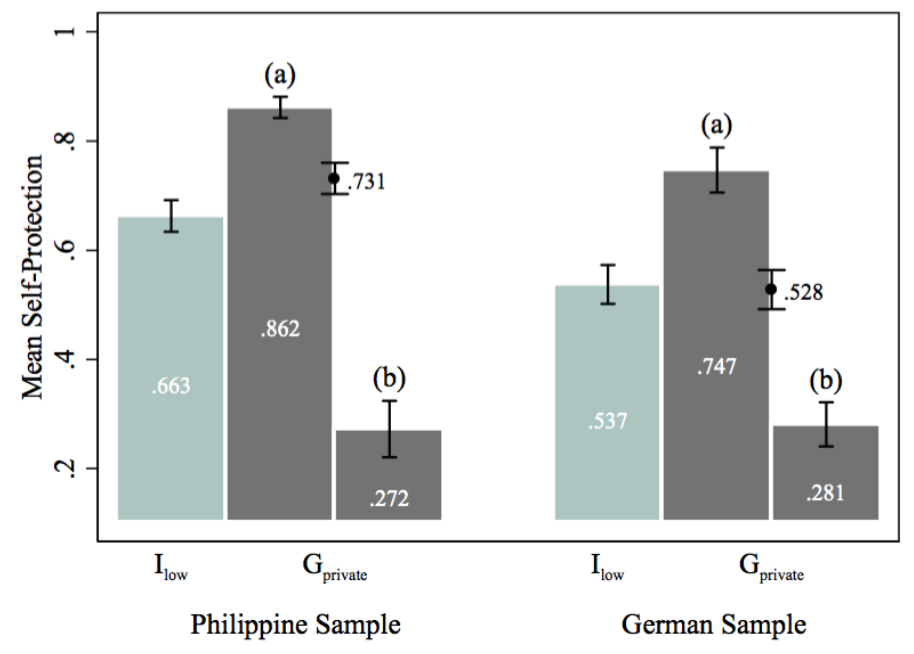

FIGURE 3. MEAN SELF-PROTECTION EFFORT BY SAMPLE AND BELIEFS

Notes: The bars represent the mean proportion of individuals choosing self-protection. We differentiate the group insurance treatment $G_{\text {private }}$ into those subjects expecting their group peer to provide self-protection effort (a) and those not expecting this (b). The unconditioned result of $G_{\text {private }}$ is positioned between the conditioned (a) and (b) results. Error bars indicate standard errors of the mean.

Hypothesis 3.-Our discussion about pro-social preferences in group mechanisms (see Section II.D) emphasized the role of beliefs about other group members. Reciprocal fairness concerns (Rabin 1993) and inequity aversion (Fehr and Schmitt 1999) both imply that the motivation to provide selfprotection effort should increase with beliefs about group peers. In Figure 3, we therefore condition self-protection decisions under treatment $G_{\text {private }}$ on beliefs about the group peer's self-protection decision. ${ }^{24}$ In contrast to the treatments related to hypotheses $H 1$ and $H 2$, beliefs do not vary exogenously

\footnotetext{
${ }^{24}$ Beliefs about group peer's self-protection decision were always elicited prior to a participant's own choice.
} 
and effects should not be interpreted as causal. In 78 percent (Philippines) and 53 percent (Germany) of the cases, the participants express positive beliefs and those might not be comparable with the rest. Nevertheless, the comparison may reveal who contributes to efficiency of $G_{\text {private }}$.

The patterns we find are very similar between the Philippine and the German samples. First, when individuals exhibit positive beliefs (bar (a) in Figure 3), self-protection levels are considerably higher than with negative beliefs (bar (b) in Figure 3). Second, relative to the average under the lowcoverage individual contract $I_{l o w}$, the self-protection probability for those with positive beliefs is substantially higher both in the Philippines $(+19.9$ percentage points, $p=0.000)$ and in Germany $(+21$ percentage points, $p=0.0001$ ). The effect is reversed if individuals exhibit negative beliefs. Here, the likelihood to provide self-protection effort clearly drops below those observed under the individual scheme $I_{\text {low }}$ and are more consistent with self-interested behavior. It hence seems that the efficiency improvements observed when testing $H 2$ are driven by those individuals with positive beliefs, which is what we expected under $H 3$. Differences in the distribution of beliefs across the two samples also seem to explain differences in the average performance of the group scheme across the samples. Our empirical findings match the theoretical considerations in Section II and the simulation results in Section III, lending credibility to the interpretation that individuals are motivated by pro-social motives, which increase with positive beliefs about other group members. ${ }^{25}$

\section{Pro-social versus Strategic Motivation}

In our design of $G_{\text {private }}$ we ensured that the individual self-protection effort is unobservable by other participants and we emphasized this fact in our instructions. Hence, motivation to provide effort under the group scheme should be driven only by pro-social preferences, not by strategic concerns such as fear of punishment. ${ }^{26}$ Our results so far suggest that pro-social motives lead to efficiency improvements and that those are stronger in the non-anonymous sample on the Philippines. Efficiency improvements, however, could be different when strategic motives are present. The literature on joint liability groups discusses such motives, particularly for credit markets (e.g., Giné and Karlan 2014). The main argument is that punishment within groups might be feasible because information asymmetries are less severe between groups of agents than between agent and principal. We therefore included an additional treatment in our experiment where effort choices were revealed to group members $\left(G_{\text {public }}\right)$. This introduces at least two strategic concerns. One is that group members can react on each other's effort choice across the three rounds. This should hold both in the anonymous lab and in the

\footnotetext{
${ }^{25}$ Since beliefs about group peer's self-protection decisions are not exogenously varied we might be concerned with such beliefs confounding with general levels of altruism. Altruism might increase the probability to provide self-protection effort and at the same time relate to the likelihood of participants to exhibit positive beliefs. We elicited a psychometric measure representing altruism within the Big Five construct "Agreeableness" developed by Rammstedt and John (2007) in the Philippine sample and find no statistically significant correlation with beliefs. Similarly, in the German sample, we elicited contributions to charity in the last year as a measure of altruism (see DellaVigna, List, and Malmendier 2012 for a discussion on the relationship between charitable giving and altruism). Here we also find no statistically significant correlation with beliefs. These analyses are available from the authors upon request. bers.

${ }^{26}$ While this argument holds in both samples, privacy was even more salient in the lab setting due to the anonymity of group mem-
} 
non-anonymous field setting. The other concern is that non-anonymous participants in the Philippines might be motivated by image concerns when interacting with fellow villagers.

Figure 4 shows self-protection probabilities for $G_{\text {private }}$ and $G_{\text {public }}$ in our two samples. Again, results are presented separately for those with positive (a) and negative (b) beliefs. Overall means by treatment are presented between (a) and (b) bars. On average, we observe slightly higher selfprotection effort provision in the Philippines when self-protection decisions are observable $\left(G_{\text {public }}\right)$ compared to the non-observable case $G_{\text {private }}(p=0.0429)$. There is no such difference in the German sample $(p=0.511)$.

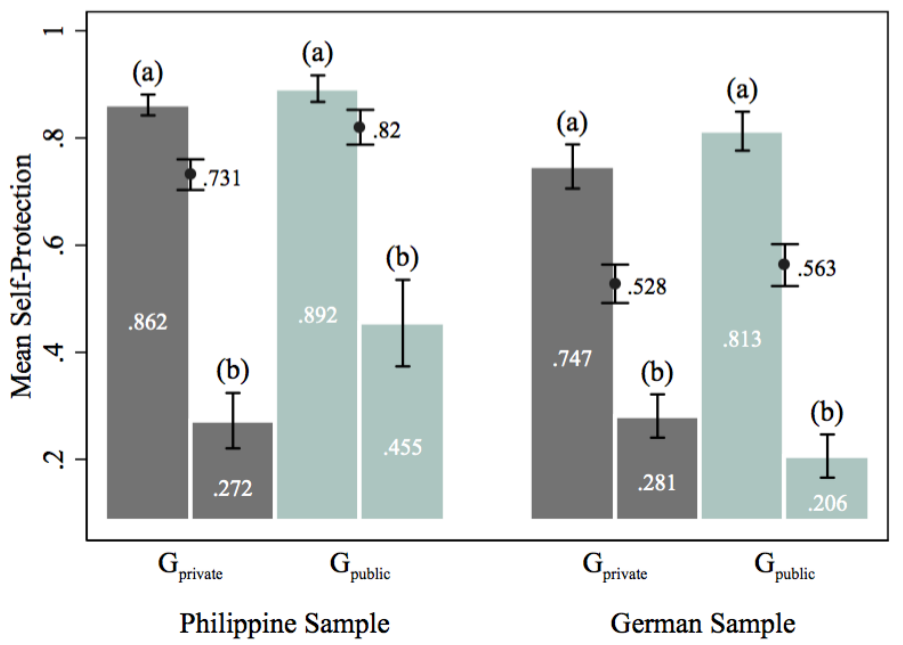

FIGURE 4. MEAN SELF-PROTECTION EFFORT BY SAMPLE, BELIEFS, AND OBSERVABILITY

Notes: The bars represent the mean proportion of individuals choosing self-protection. We differentiate the group insurance treatments into those subjects expecting their group peer to provide self-protection effort (a) and those not expecting this (b). The unconditioned results of $G_{\text {private }}$ and $G_{\text {public }}$ are positioned between the conditioned (a) and (b) results. Error bars indicate standard errors of the mean.

The conditioned self-protection decisions reveal that self-protection for those with positive beliefs is very similar across treatments in both samples $(p=0.334$ for the Philippines and $p=0.231$ for the German sample). Those with negative beliefs exhibit differences only for the Philippine sample. Here, self-protection is 18.3 percentage points higher $(p=0.0597)$ when effort choices are revealed, suggesting that in particular those with low initial pro-social motivation behave strategically. However, this interpretation might be flawed, as beliefs themselves can be influenced by the observability of decisions. We do not find a significant change in beliefs when implementing $G_{\text {public }}$, either in the Philippines (84 percent positive beliefs under $G_{\text {public }}$ versus 78 percent under $G_{\text {private }}, p=0.186$ ) or in the German sample (59 percent versus 53 percent, $p=0.244$ ). Nevertheless, we restrict our main conclusion to the observation that when introducing strategic concerns, further efficiency improvements can be observed in non-anonymous groups.

\section{Network Strength}

We discussed the role of pro-social and strategic motives within group schemes in our results above. However, the composition of groups might be an important factor for the strength of these 
motives. Whether groups consist of random individuals or close friends might change the motivation to provide self-protection effort. In the Philippine sample, we therefore experimentally varied the composition of groups within the group insurance treatments. To achieve a meaningful variation in "network strength," we exploit our invitation procedure which ensures that invited participants always appear in pairs (i.e., friends or relatives). Whenever we implemented a group insurance treatment we made sure that one half of the participants would be matched with their peer (strong group) and the other half with a random villager (weak group). We would expect both pro-social and strategic motives to become more pronounced in strong groups and for the efficiency of $G_{\text {public }}$ and $G_{\text {private }}$ to be larger in strong groups than in weak groups.

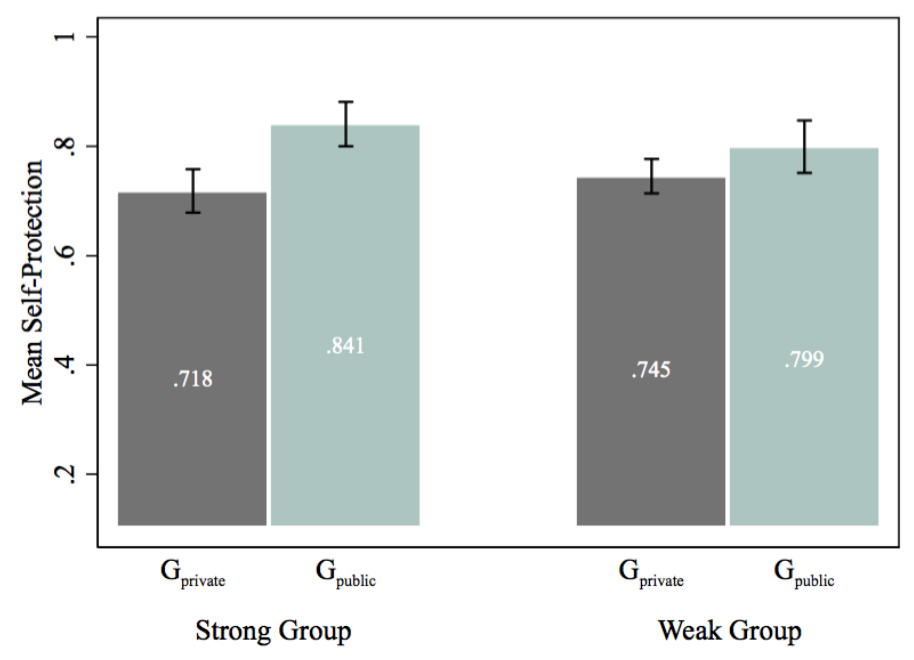

FIGURE 5. MEAN SELF-PROTECTION EFFORT BY GROUP COMPOSITION mean.

Notes: The bars represent the mean proportion of individuals choosing self-protection. Error bars indicate standard errors of the

Figure 5 shows average self-protection probabilities in $G_{\text {public }}$ and $G_{\text {private }}$ by group composition. In both treatments, willingness to provide self-protection effort is not significantly different across group compositions ( $p=0.536$ under $G_{\text {private }}, p=0.496$ in $G_{p u b l i c}$ ). The effect of revealing selfprotection decisions (i.e., difference between $G_{\text {private }}$ and $G_{\text {public }}$ ), however, appears to be more pronounced in strong groups $(p=0.0331)$. This is consistent with the fact that beliefs are about 10 percentage points higher ( $p<0.0285$ for all comparisons) only for the strong groups under $G_{p u b l i c}$. In fact, it is plausible that strategic effects, such as image concerns, play a stronger role for those who interact more frequently in real life. Overall, however, the differences between weak and strong groups are not large and efficiency of the group scheme in the Philippine setting does not seem to depend heavily on group composition. One explanation might be that even random individuals within small villages in the Philippines often know and interact with each other.

\section{E. Dynamic Effects}

So far, we pooled our analyses across rounds. We took potential correlation over time into account by clustering standard errors at the session (Philippines) and individual (Germany) level. Never- 
theless, pooling observations might mask differences in treatment effects over time that could occur, for example, through learning or-when revealing effort choice in the group scheme $\left(G_{\text {public }}\right)$ through strategic interaction. We analyze the stability of treatment effects in Figure 6, which presents results separately for rounds four through six. Testing average self-protection by treatment for differences across rounds shows that none of them changes significantly. The size and direction of our main treatment effects also remain very robust (compare online Appendix Table E1 for regression coefficients).

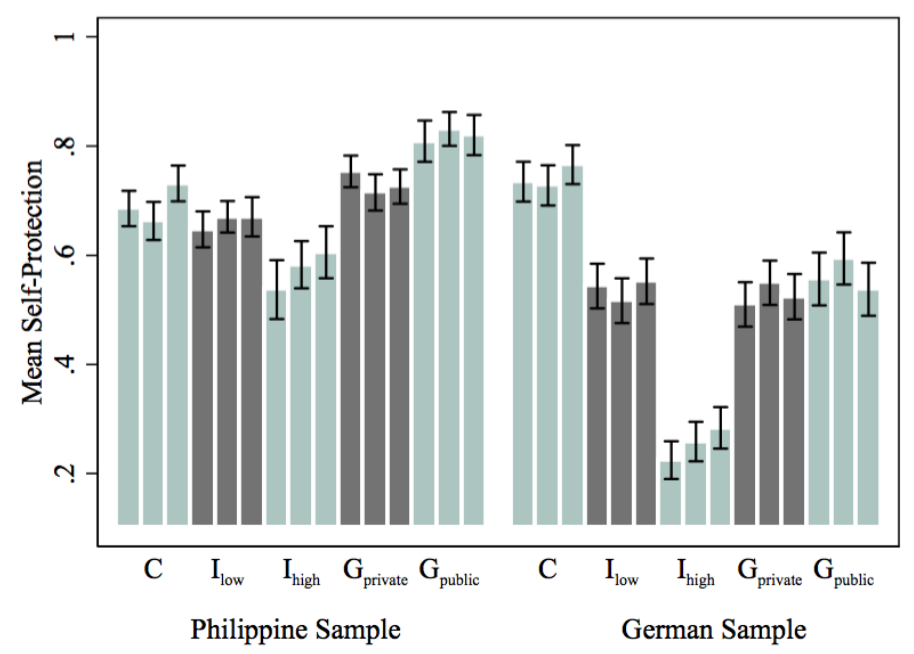

FIGURE 6. MEAN SELF-PROTECTION EFFORT BY ROUND mean.

Notes: The bars represent the mean proportion of individuals choosing self-protection. Error bars indicate standard errors of the

Moreover, we are interested in the impact of experience in previous rounds of the experiment on decisions. As subjects move through the experiment, they gather experience on the consequences of their choices that might render certain aspects more salient than others, thus evoking behavioral responses (see, e.g., Bordalo, Gennaioli, and Shleifer 2012). In Table 4, we derive estimates of previous rounds' self-protection decisions, shock experience, and their interactions. ${ }^{27}$ The results are, again, very consistent between the Philippine and the German samples. The large and highly significant coefficient on cumulative self-protection decisions in prior rounds illustrates that there is a high autocorrelation of decisions over time in both samples.

In addition, the more losses a subject experienced in previous rounds, the higher the likelihood of providing self-protection effort in the current round. Experiencing one additional loss increases the likelihood to provide self-protection effort by 7.1 percentage points for the Philippine and 16.8 percentage points for the German sample. Interestingly, this holds only when shocks are experienced without prior self-protection. With prior self-protection the effect of loss experience is negative. This finding is in line with theoretical results by Briys and Schlesinger (1990). Having provided selfprotection effort before a loss makes the bad outcome even worse, despite reducing its probability.

\footnotetext{
${ }^{27}$ These covariates all depend on self-protection decisions in the past and are thus endogenous to the treatment status. As selfprotection decisions are auto-correlated, these endogenous controls might bias the treatment effect estimates. However, our main point here is to illustrate the correlation of experience with current decisions, not to estimate treatment effects.
} 
Experiencing this situation seems to make it more salient and hence reduces the willingness to provide self-protection effort compared with shock experience in the absence of self-protection. We also observe that the more often the self-protection option has been selected in the past, the more likely subjects are to provide self-protection effort in the current round. This correlation of decisions across rounds is not surprising given that we expect certain risk-averse types to make consistent decisions.

TABLE 4-PROBIT MODELS FOR SELF-PROTECTION AND EXPERIMENT HISTORY

\begin{tabular}{lccc}
\hline & Philippine sample & & German sample \\
${$\cline { 1 - 2 }$} }$ & $(1)$ & $(2)$ \\
\hline Cumulative & $0.161^{* * *}$ & $0.201^{* * *}$ \\
self-protection decisions & $(0.00548)$ & $(0.0146)$ \\
Cumulative & $0.0706^{* * *}$ & $0.168^{* * *}$ \\
losses & $(0.0123)$ & & $(0.0235)$ \\
Cumulative losses & $-0.111^{* * *}$ & & $-0.100^{* * *}$ \\
under self-protection & $(0.0179)$ & & $(0.0335)$ \\
\hline Treatment dummies & Yes & Yes \\
Controls & Yes & & Yes \\
\hline Observations & a & 2,973 & \\
logLik & $-1,120$ & & -745 \\
\hline
\end{tabular}

Notes: Probit models are used with the dependent variable set to 1 if the subject chooses to provide self-protection effort. The results are provided in terms of marginal effects. Standard errors (reported in parentheses) are corrected for clustering at the session level for the Philippine sample and at the individual level for the German sample. This also controls for a possible correlation of self-protection decisions across rounds. Control variables are sex, age, whether the subject is responsible for household financial decision-making, annual income, numeracy, a risk-aversion measure resulting from Binswanger (1980) lottery choices, a questionnaire item score for ambiguity aversion, round dummies, and an indicator whether the village experienced Typhoon Haiyan before the experiment (Philippines only).

Significant at the 1 percent level.

${ }^{* *}$ Significant at the 5 percent level.

Significant at the 10 percent level.

\section{Conclusions}

This paper shows that pro-social preferences within groups of agents can be exploited by a principal to alleviate moral hazard. Typically, only the exposure to the principal's risk motivates agents to provide effort that increases the likelihood of a favorable state of the world. This arrangement, however, is undesirable, especially for risk-averse agents. Our theoretical intuition illustrates that agents who care about the outcomes of their peers will internalize the effect of effort choices on these peers. This induces stronger incentives against moral hazard than individual risk exposure would suggest and potentially leads to improvements in the tradeoff between individual risk exposure and overall efficiency.

Our results from two large independent behavioral experiments - one with rural villagers from the Philippines and one with university students from Germany-are remarkably consistent with this logic. We establish empirically that effort provision decreases when making payoffs of agents less state-dependent, which is in line with moral hazard. We then show that a joint liability group scheme achieves significantly higher levels of effort provision than its risk-exposure would suggest. In particular, those with positive beliefs about their group peer's effort are more likely to provide effort themselves. This suggests that pro-social motives increase with positive beliefs about other group members, which is consistent with reciprocal fairness concerns (Rabin 1993) or, as differences in peers' effort generates inequity in outcomes, inequity aversion (Fehr and Schmidt 1999). Other explanations 
such as preferences to conform to a social norm (Messick 1999; Schram and Charness 2015) are also in line with our observations.

These findings are promising and - if externally valid — have implications for contract design in markets exposed to moral hazard. Our theory, however, implies that effort provision can be sustained only under high levels of pro-social motivation. In a similar vein, the empirical results suggest that trust in others' effort provision plays a large role in one's own behavior. It is hence straightforward to ask whether results would be robust to alternative group compositions with a different relationship structure. To some extent we answer this question by experimentally varying the group composition in the Philippine sample. In our case it does not make a large difference whether groups consist of close friends and relatives or random villagers. However, even random individuals within a small village might have a strong relationship and it would be naive to assume that this is representative for all possible scenarios. When moving the experiment from rural villages to a computer laboratory with anonymous students, the advantage of the group scheme-while still present - is already less pronounced. There might be group settings where members are entirely self-interested or where social incentives even turn negative, for example out of envy or competitiveness. These considerations call for implementation in high trust settings with positive motivation of group members.

A related point is that in our experiment groups consist of two individuals and it is not clear how the results would change with more members. Individual residual risk is reduced as group size increases, such that incentives for effort provision of self-interested individuals should also decrease. Whether pro-social preferences can maintain high levels of effort under these circumstances is an open question, given that positive beliefs and pro-sociality might diffuse once groups become too large. The literature on public good experiments suggests that there is a negative group size effect on willingness to contribute; however, even very large groups seem capable of sustaining some positive contributions (see, for example, Isaac and Walker 1988; Weimann et al. 2012), so there are reasons to believe that joint liability can also work in groups with $n>2$.

Although derived from an insurance experiment, our empirical findings relate to discussions in other areas. In particular, the literature on employment contracts (Itoh 2004; Bartling and Siemens 2010; Englmaier and Wambach 2010; Nielson and Stowe 2010; Bartling 2011, 2012) has considered the implications of pro-social concerns between agents for contract design. ${ }^{28}$ This literature follows a logic similar to our paper. For example, Bartling (2011) suggests that optimal contracts should include team components if agents care for their relative payoffs. Our experiment contributes to the relevance of these theories, especially as we are not aware of any other work testing such joint liability schemes empirically. The literature on group credits (e.g., Karlan 2005; Karlan 2007; Al-Azzam, Hill, and Sarangi 2012; Bauer, Chytilová, and Morduch 2012; Giné and Karlan 2014) also discusses the effi-

\footnotetext{
${ }^{28}$ In contrast to our paper, this literature exclusively focusses on inequity aversion as a driver of social preferences. We also provide an intuition based on alternative concepts such as fairness concerns (Rabin 1993).
} 
ciency of joint liability against moral hazard, but focusses on the role of strategic concerns. ${ }^{29}$ The argument is that better information or monitoring within groups allows agents to punish or reward each other much more easily than the principal could. In contrast to pro-social motivation, efficiency improvements based on strategic interaction are limited to situations where moral hazard is truly observable. On the other hand, including strategic interaction might strengthen incentives for effort provision and it is interesting to compare joint liability with and without strategic interaction. In an additional experimental treatment, we therefore reveal effort choices of agents within groups to trigger strategic motives. We find positive effects of making this information public particularly in the nonanonymous sample of villagers from the Philippines. This is not surprising, as strategic motives should be less salient when agents are anonymous. Taken together, these results suggest that strategic interaction might further improve effort provision in group schemes.

In this paper we consider a standard moral hazard problem: agents have little incentive to maximize the probability of a positive outcome for their employer, creditor, or insurer. This ex-ante type of moral hazard is not the only form of moral hazard, though. Insurance contracts are an example where also ex-post moral hazard plays a role. This means that agents have incentives to negatively affect the cost faced by the insurer after the state of the world is realized, for example, by reporting false claims or by using more expensive medical care. Even though individual incentives have been shown to work similarly in this context both theoretically (Petretto 1999) as well as empirically (Manning et al. 1987), the virtue of group contracts for ex-post moral hazard is an open question.

Another challenge for successful implementation of group schemes might be high levels of individualism, particularly in high-income countries (Gorodnichenko and Roland 2016), which are potentially related to preferences for individual financial contracts. This is consistent with the fact that joint liability financial contracts are basically nonexistent in high-income countries. Innovative "peer-topeer" insurance schemes are a counterexample, but still have a low market share. The situation is different in developing countries. Social groups already assume strong roles in financial transactions (Fafchamps and Lund 2003) and community-based risk management is very common (Bhattamishra and Barrett 2010). This is a good basis for rolling out group insurance and credit products. Joint liability can furthermore help to keep individual risk exposure low which is particularly important for lowincome households. To assess the potential of joint liability in practice, more evaluations of such schemes in different contexts are needed, especially as rigorous evidence remains scarce.

The interpretation of our empirical results naturally rests on some assumptions, since randomizing all potentially interesting influencing factors is hardly possible. The two experiments analyzed in this paper exogenously varied several essential features, but there remain factors, such as pro-social preferences or beliefs, which are difficult or even impossible to manipulate randomly as they usually evolve endogenously and in a non-trivial way. This makes it very important to think about the inter-

\footnotetext{
${ }^{29}$ Giné and Karlan (2014) even exploit a large randomized controlled trial to test the incentive effect of joint liability in credit groups on repayment performance.
} 
pretation of results theoretically in order to judge its plausibility and generalizability. We therefore provide a theoretical intuition, derive testable hypotheses, and link them to our empirical findings. The fact that we reproduce the main results across two independent and very different settings lends further credibility to our findings. 


\section{References}

Abbink, K., Irlenbusch, B., and E. Renner, 2006, Group Size and Social Ties in Microfinance Institutions, Economic Inquiry, 44(4): 614-628.

Adams, W., Einav, L., and J. Levin, 2009, Liquidity Constraints and Imperfect Information in Subprime Lending, American Economic Review, 99(1): 49-84.

Al-Azzam, M., R. C. Hill, and S. Sarangi, 2012, Repayment Performance in Group Lending: Evidence from Jordan, Journal of Development Economics, 97(2): 404-414.

Andersson, O., H. J. Holm, J.-R. Tyran, and E. Wengström, 2013, Risking Other People's Money, CEPR Discussion Paper No. DP9743.

Andersson, O., H. J. Holm, J.-R. Tyran, and E. Wengström, 2016, Deciding for Others Reduces Loss Aversion, Management Science, 62(1): 29-36.

Arnott, R., and J. E. Stiglitz, 1991, Moral Hazard and Nonmarket Institutions: Dysfunctional Crowding Out of Peer Monitoring, American Economic Review, 81(1): 179-190.

Arrow, K. J., 1963, Uncertainty and the Welfare Economics of Medical Care, American Economic Review, 53(5): 941-973.

Ashraf, N., 2009, Spousal Control and Intra-Household Decision Making: An Experimental Study in the Philippines, American Economic Review, 99(4): 1245-1277.

Autor, D., Duggan, M., and J. Gruber, 2014, Moral Hazard and Claims Deterrence in Private Disability Insurance, American Economic Journal: Applied Economics, 6(4): 110-141.

Babcock, P., K. Bedard, G. Charness, J. Hartman, and H. Royer, 2015, Letting Down the Team? Social Effects of Team Incentives, Journal of the European Economic Association, 13(5): 841-870.

Barr, A., and G. Genicot, 2008, Risk Sharing, Commitment, and Information: An Experimental Analysis, Journal of the European Economic Association, 6(6): 1151-1185.

Barseghyan, L., Molinari, F., O'Donoghue, T., and J. C. Teitelbaum, 2013, The Nature of Risk Preferences: Evidence from Insurance Choices, American Economic Review, 103(6): 2499-2529.

Bartling, B., 2011, Relative Performance or Team Evaluation? Optimal Contracts for OtherRegarding Agents, Journal of Economic Behavior and Organization, 79(3): 183-193.

Bartling, B., 2012, Multi-Tasking and Inequity Aversion in the Linear-Exponential-Normal Moral Hazard Model, Economics Letters, 116(3): 523-525.

Bartling, B., and F. A. von Siemens, 2010, The Intensity of Incentives in Firms and Markets: Moral Hazard with Envious Agents, Labour Economics, 17(3): 598-607.

Bauer, M., J. Chytilová, and J. Morduch, 2012, Behavioral Foundations of Microcredit: Experimental and Survey Evidence from Rural India, American Economic Review, 102(2): 1118-1139.

Becker, G. M., M. H. Degroot, and J. Marschak, 1964, Measuring Utility by a Single-response Sequential Method, Behavioral Science, 9(3): 226-232.

Berger, L. A., and C. Hershey, 1994, Moral Hazard, Risk Seeking, and Free Riding, Journal of Risk and Uncertainty, 9(2): 173-186.

Bhattamishra, R., and C. B. Barrett, 2010, Community-Based Risk Management Arrangements: A Review, World Development, 38(7): 923-932. 
Biais, B., Mariotti, T., Rochet, J.-C., and S. Villeneuve, 2010, Large Risks, Limited Liability, and Dynamic Moral Hazard, Econometrica, 78(1): 73-118.

Binswanger, H. P., 1980, Attitudes Toward Risk: Experimental Measurement in Rural India, American Journal of Agricultural Economics, 62(3): 395-407.

Bolton, G. E., and A. Ockenfels, 2000, ERC: A Theory of Equity, Reciprocity, and Competition, American Economic Review, 90(1): 166-193.

Bordalo, P., N. Gennaioli, and A. Shleifer, 2012, Salience Theory of Choice under Risk, Quarterly Journal of Economics, 127(3): 1243-1285.

Briys, E., and H. Schlesinger, 1990, Risk Aversion and the Propensities for Self-Insurance and SelfProtection, Southern Economic Journal, 57(2): 458-467.

Briys, E., H. Schlesinger, and J.-M. Graf v.d. Schulenburg, 1991, Reliability of Risk Management: Market Insurance, Self-Insurance, and Self-Protection Reconsidered, Geneva Papers on Risk and Insurance Theory, 16(1): 45-58.

Brown, M., Falk, A., and E. Fehr, 2004, Relational Contracts and the Nature of Market Interactions, Econometrica, 72(3): 747-780.

Brown, M., and C. Zehnder, 2007, Credit Reporting, Relationship Banking, and Loan Repayment, Journal of Money, Credit and Banking, 39(8): 1883-1918.

Chaudhuri, A., 2010, Sustaining Cooperation in Laboratory Public Goods Experiments: A Selective Survey of the Literature, Experimental Economics, 14(1): 47-83.

Che, Y.-K., and S.-W. Yoo, 2001, Optimal Incentives for Teams, American Economic Review, 91(3): $525-541$.

Chiappori, P.-A., and B. Salanié, 2000, Testing for Asymmetric Information in Insurance Markets, Journal of Political Economy, 108(1): 56-78.

Clarke, D. J., 2011, Reinsuring the Poor: Group Microinsurance Design and Costly State Verification, Department of Economics Discussion Paper Series, No. 573, University of Oxford.

Cole, S., X. Giné, J. Tobacman, R. Townsend, P. Topalova, and J. Vickery, 2013, Barriers to Household Risk Management: Evidence from India, American Economic Journal: Applied Economics, 5(1): 104-135.

Courbage, C., 2001, Self-Insurance, Self-Protection and Market Insurance Within the Dual Theory of Choice, Geneva Papers on Risk and Insurance Theory, 26(1): 43-56.

Cummings, R. G., G. W. Harrison, and E. E. Rutström, 1995, Homegrown Values and Hypothetical Surveys: Is the Dichotomous Choice Approach Incentive-Compatible? American Economic Review, 85(1): 260-266.

DellaVigna, S., List, J. A., and U. Malmendier, 2012, Testing for Altruism and Social Pressure in Charitable Giving, Quarterly Journal of Economics, 127(1): 1-56.

Dewatripont, M., Jewitt, I., and J. Tirole, 1999, The Economics of Career Concerns, Part I: Comparing Information Structures, Review of Economic Studies, 66(1): 183-198.

Dionne, G., and L. Eeckhoudt, 1985, Self-Insurance, Self-Protection and Increased Risk Aversion, Economics Letters, 17(1-2): 39-42. 
Dionne, G., P.-C. Michaud, and M. Dahchour, 2013, Separating Moral Hazard from Adverse Selection and Learning in Automobile Insurance: Longitudinal Evidence from France, Journal of the European Economic Association, 11(4): 897-917.

Eckel, C. C., and P. J. Grossmann, 2005, Managing Diversity by Creating Team Identity, Journal of Economic Behavior and Organization, 58(3): 371-392.

Ehrlich, I., and G. S. Becker, 1972, Market Insurance, Self-Insurance, and Self-Protection, Journal of Political Economy, 80(4): 623-648.

Englmaier, F., and S. Leider, 2012, Contractual and Organizational Structure with Reciprocal Agents, American Economic Journal: Microeconomics, 4(2): 146-183.

Englmaier, F., and A. Wambach, 2010, Optimal Incentive Contracts under Inequity Aversion, Games and Economic Behavior, 69(2): 312-328.

Fafchamps, M., and S. Lund, 2003, Risk-sharing Networks in Rural Philippines, Journal of Development Economics, 71(2): 261-287.

Fehr, E., M. Brown, and C. Zehnder, 2009, On Reputation: A Microfoundation of Contract Enforcement and Price Rigidity, Economic Journal, 119 (536): 333-353.

Fehr, E., and K. M. Schmidt, 1999, A Theory of Fairness, Competition, and Cooperation, Quarterly Journal of Economics, 114(3): 817-868.

Fischbacher, U., 2007, z-Tree: Zurich Toolbox for Ready-made Economic Experiments, Experimental Economics, 10(2): 171-178.

Fischbacher, U., S. Gächter, and E. Fehr, 2001, Are People Conditionally Cooperative? Evidence from a Public Goods Experiment, Economics Letters, 71(3): 397-404.

Fudenberg, D., and D. K. Levine, 2012, Fairness, Risk Preferences and Independence: Impossibility Theorems, Journal of Economic Behavior \& Organization, 81(2): 606-612.

Ghatak, M., and T. Guinnane, 1999, The Economics of Lending with Joint Liability: Theory and Practice, Journal of Development Economics, 60(1): 195-228.

Giné, X., J. Goldberg, and D. Yang, 2012, Credit Market Consequences of Improved Personal Identification: Field Experimental Evidence from Malawi, American Economic Review, 102(6): 29232954.

Giné, X., and D. S. Karlan, 2014, Group versus Individual Liability: Short and Long Term Evidence from Philippine Microcredit Lending Groups, Journal of Development Economics, 107(2014): 6583.

Goette, L., D. Huffman, S. Meier, and M. Sutter, 2012, Competition Between Organizational Groups: Its Impact on Altruistic and Antisocial Motivations, Management Science, 58(5): 948-960.

Gong, M., J. Baron, and H. Kunreuther, 2009, Group Cooperation under Uncertainty, Journal of Risk and Uncertainty, 39(3): 251-270.

Gorodnichenko, Y., and G. Roland, 2016, Culture, Institutions and the Wealth of Nations, Review of Economics and Statistics, forthcoming.

Guillen, P., D. Merrett, and R. Slonim, 2015, A New Solution for the Moral Hazard Problem in Team Production, Management Science, 61(7): 1514-1530. 
Harrison, G. W., and E. E. Rutström, 2008, Risk Aversion in the Laboratory, Research in Experimental Economics, 12: 41-196.

Hermes, N., and R. Lensink, 2007, The Empirics of Microfinance: What Do We Know, Economic Journal, 117(517): F1-F10.

Herweg, F., Müller, D., and P. Weinschenk, 2010, Binary Payment Schemes: Moral Hazard and Loss Aversion, American Economic Review, 100(5): 2451-2477.

Hiebert, D. L., 1989, Optimal Loss Reduction and Increases in Risk Aversion, Journal of Risk and Insurance, 56(2): 300-305.

Holmström, B., 1979, Moral Hazard and Observability, Bell Journal of Economics, 10(1): 74-91.

Holt, C. A., and S. K. Laury, 2002, Risk Aversion and Incentive Effects, American Economic Review, 92(5): 1644-1655.

Isaac, R. M., and J. M. Walker, 1988, Group Size Effects in Public Goods Provision: The Voluntary Contributions Mechanism, Quarterly Journal of Economics, 103 (1): 179-199.

Itoh, H., 2004, Moral Hazard and Other-Regarding Preferences, Japanese Economic Review, 55(1): $18-45$.

Jullien, B., B. Salanié, and F. Salanié, 1999, Should More Risk-Averse Agents Exert More Effort?, Geneva Papers on Risk and Insurance Theory, 24(1): 19-28.

Karlan, D. S., 2005, Using Experimental Economics to Measure Social Capital and Predict Financial Decisions, American Economic Review, 95(5): 1688-99.

Karlan, D., 2007, Social Connections and Group Banking, Economic Journal, 117(517): 52-84.

Kessler, J. B., and S. Leider, 2010, Norms and Contracting, Management Science, 58(1): 62-77.

Konrad, K. A., and S. Skaperdas, 1993, Self-Insurance and Self-Protection: A Nonexpected Utility Analysis, Geneva Papers on Risk and Insurance Theory, 18(2): 131-146.

Köszegi, B., 2014, Behavioral Contract Theory, Journal of Economic Literature, 52(4): 1075-1118.

Kramer, R. M., and M. B. Brewer, 1986, Social Group Identity and the Emergence of Cooperation in Resource Conservation Dilemmas, in: H. Wilke, D. Messick, and C. Rütte (eds.), Psychology of Decision and Conflict, Vol. 3, Experimental Social Dilemmas (Frankfurt am Main: Verlag Peter Lang), pp. 205-230.

Lakdawalla, D. N., and G. Zanjani, 2005, Insurance, Self-Protection, and the Economics of Terrorism, Journal of Public Economics, 89(9-10): 1891-1905.

Levitt, S. D., and J. A. List, 2007, What Do Laboratory Experiments Measuring Social Preferences Reveal About the Real World?, Journal of Economic Perspectives, 21(2): 153-174.

Liu, L., and J. Meyer, 2012, Decreasing Absolute Risk Aversion, Prudence and Increased Downside Risk Aversion, Journal of Risk and Uncertainty, 44(3): 243-260.

Lohse, T., J. R. Robledo, and U. Schmidt, 2012, Self-Insurance and Self-Protection as Public Goods, Journal of Risk and Insurance, 79(1): 57-76.

Manning, W. G., J. P. Newhouse, N. Duan, E. B. Keeler, and A. Leibowitz, 1987, Health Insurance and the Demand for Medical Care: Evidence from a Randomized Experiment, American Economic Review, 77(3): 251-277.

Messick, D. M., 1999, Alternative Logics for Decision Making in Social Settings, Journal of Economic Behavior and Organization, 39(1): 11-28. 
Miller, L., D. E. Meyer, and J. T. Lanzetta, 1969, Choice Among Equal Expected Value Alternatives: Sequential Effects of Winning Probability Level on Risk Preferences, Journal of Experimental Psychology, 79(3): 419-423.

Muermann, A., and H. Kunreuther, 2008, Self-Protection and Insurance with Interdependencies, Journal of Risk and Uncertainty, 36(2): 103-123.

Nielson, W. S., and J. Stowe, 2010, Piece-Rate Contracts for Other-Regarding Workers, Economic Inquiry, 48(3): 575-586.

Pauly, M. V., 1968, The Economics of Moral Hazard: Comment, American Economic Review, 58(3): 531-537.

Pauly, M. V., 1974, Overinsurance and Public Provision of Insurance: The Roles of Moral Hazard and Adverse Selection, Quarterly Journal of Economics, 88(1): 44-62.

Petretto, A., 1999, Optimal Social Health Insurance with Supplementary Private Insurance, Journal of Health Economics, 18(6): 727-745.

Rabin, M., 1993, Incorporating Fairness into Game Theory and Economics, American Economic Review, 83(5): 1281-1302.

Rammstedt, B., and O. P. John, 2007, Measuring Personality in One Minute or Less: A 10-item Short Version of the Big Five Inventory in English and German, Journal of Research in Personality, 41(1): 203-212.

Republic of the Philippines, 2013, Wage Order No. RBVI-21 as of October 30, 2013, Department of Labor and Employment, National Wages and Productivity Commission, Regional Tripartite Wages and Productivity Board, Regional Board No. VI, Iloilo City, Philippines.

Republic of the Philippines, 2014, Philippine Standard Geographic Codes (PSGC), Philippine Statistics Authority, National Statistical Coordination Board, Makati City, Philippines.

Rothschild, M., and J. Stiglitz, 1976, Equilibrium in Competitive Insurance Markets: An Essay on the Economics of Imperfect Information, Quarterly Journal of Economics, 90(4): 629-649.

Rowell, D., and L. B. Connelly, 2012, A History of the Term "Moral Hazard," Journal of Risk and Insurance, 79(4): 1051-1075.

Saito, K., 2013, Social Preferences under Risk: Equality of Opportunity versus Equality of Outcome, American Economic Review, 103(7): 3084-3101.

Schmidt, H., K. Voigt, and D. Wikler, 2010, Carrots, Sticks, and Health Care Reform-Problems with Wellness Incentives, New England Journal of Medicine, 362(3): 1-3.

Schram, A., and G. Charness, 2015, Inducing Social Norms in Laboratory Allocation Choices, Management Science, 61(7): 1531-1546.

Shavell, S., 1979, On Moral Hazard and Insurance, Quarterly Journal of Economics, 93(4): 541-562.

Shearer, B., 2004, Piece Rates, Fixed Wages and Incentives: Evidence from a Field Experiment, Review of Economic Studies, 71(2): 513-534.

Spence, M., and R. Zeckhauser, 1971, Insurance, Information, and Individual Action, American Economic Review, 61(2): 380-387.

Sweeney, G. H., and T. R. Beard, 1992, The Comparative Statics of Self-Protection, Journal of Risk and Insurance, 59(2): 301-309. 
Visaria, S., 2009, Legal Reform and Loan Repayment: The Microeconomic Impact of Recovery Tribunals in India. American Economic Journal: Applied Economics, 1(3): 59-81.

Weimann, J., J. Brosig-Koch, H. Hennig-Schmidt, C. Keser, and C. Stahr, 2012, Public-good Experiments with Large Groups, FEMM Working Paper No. 9/2012.

World Bank, 2013, Fondos: Mexico's Unique Agricultural Mutual Insurance Funds, Mexico: Agriculture Insurance Market Review, Report No. 88099.

Yilma, Z., L. van Kempen, and T. de Hoop, 2012, A Perverse "Net" Effect? Health Insurance and ExAnte Moral Hazard in Ghana, Social Science \& Medicine, 75(1): 138-147.

Zeckhauser, R., 1970, Medical Insurance: A Case Study of the Trade-off between Risk Spreading and Appropriate Incentives, Journal of Economic Theory, 2(1): 10-26. 